\title{
MSET:
}

EROSION-CORROSION

Brijesh Vyas

This veport was prepared as an account of work

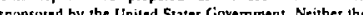

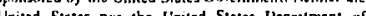
Fineror nor any Enerky, nor any or thell emplayees, nim any of then

contractos, suhcontactors, or heir enployees, makes any watrang, express or minied. or asumess any legal hahlihy or respernsibility for hie accusacy, completeness ar usefulness of any information, appasalus, product on poocess disclused, if represents that its use would not infringe privately owned rights.

Department of Nuclear Energy

Brookhaven National Laboratory

Upton, New York 11973 
TABLE OF CONTENTS

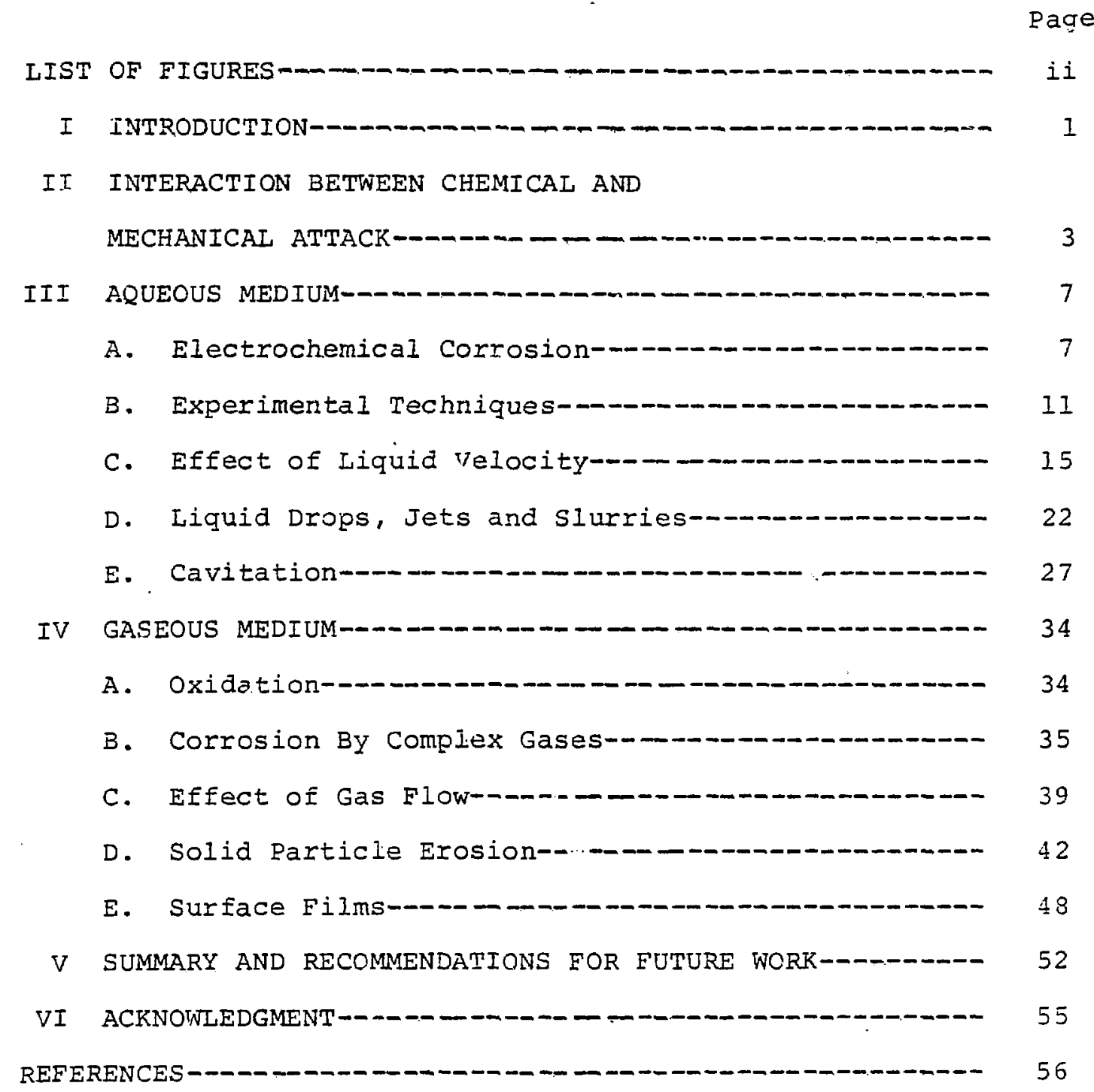




\section{LIST OF FIGURES}

FIGURE 1. Oxidation versus time of exposure (a) normal film growth; (b), film broken at 1,2 and 3 ; (c) film broken frequently, producing a linear

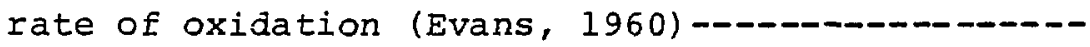

FIGURE 2. Schematic of diffusion of oxygen to the metal surface through a flowing liquid--_-

FIGURE 3. Changes in erosion-corrosion mechanism as a function of velocity of the liquid (Syrett, 1976) - - -

FIGURE 4. Possible microstreaming of the liquid (a) associatad with a single resonant cavity attached to a vibratory horn, and (b) at the edge of a vibratory horn which is placed at a distance, h, from a plane solid surface (Nyborg et al.:, 1959)

FIGURE 5. Change in current density and weight of a polished nickel sample held at a passive potential of $+600 \mathrm{mV}$ vs. SCE and exposed to ultrasonic cavitation (Preece and Vyas, 1974)--.-

FIGURE 6. Possible modifications to oxidation mechanisms due to $\mathrm{CO}_{2}$ and $\mathrm{H}_{2} \mathrm{O}$ being present in the atmosphere (Birks, 1976), "This figure was originally presented at the Fall 150th Meeting of The Electrochemical society, Inc., held in

Las Vegas, Nevada."--_-

FIGURE 7. Main flow model of $13 \mu \mathrm{m}$ diameter particles in a gas turbine first stage (Spengler et al.. 1977) -

FIGURE 8. Predicted material loss by solid particle erosion versus axial position on a rotor blade (Spengler et al. 1977) 
FIGURE 9. Interaction of oxide film thickness and particle diameter on the erosion-corrosion process when

(a) the thickness of the oxide layer is small,

(b) the thickness of the oxide layer is comparable to the particle diameter (Goebel et al..'

1977 ) - 


\section{INTRODUCTION}

Mechanical and chemical agents are the two most common modes of attack that cuase deterioration of engineering materials. Destruction of metals by chemical or electrochemical action is known as corrosion. Erosion of metals is caused by mechanical action, especially as a result of a series of independent impact events. The two modes of attack can interact in many subtle ways to effect the rate of destruction of materials and is denoted as erosion-corrosion. The current usage of the term, however, also includes purely electrochemical processes, where the rate of material attack has been increased by the physical movement of the environment such as the flow of liquids in pipes, jets, aerodynamic gas flow in turbines, etc. It is for this reason that each section will begin with corrosion of materials in a stationary environment and then add the effect of physical changes in the electrolyte and finally the effect of the impact event.

Erosion-Corrosion $(E-C)$ is a problem in a variety of dynamic environments, such as the ocean, pipelines (particularly at bends), impelless, agitators, heat exchangers orifices, nozzles, propellers, turbines, most parts of coal conversion plants, exhaust systems, etc. With the use of higher speeds and smaller sizes of hydrodynamic systems and higher temperatures in energy conversion systems, the problem of $\mathrm{E}-\mathrm{C}$ is on the rise. The problem, however, is not limited to highly sophisticated equipment, but affects the 
average person in such daily circumstances as the use of a car: The deterioration of the body of the car results from the erosion (chipping) of the paint by the grit, the uptake of salt over the exposed areas, and the corrosion at these areas in humid atmospheres (Evans, 1976). The E-C of the car body can be decreased by either using galvanized steel, thus influencing the corrosion of steel, or increasing the adhesion of paint to the metal, thus preventing the chipping of the paint (Humpherys, 1973; Russel and Kiuchi, 1978).

The deterioration of materials by corrosion or erosion by itself presents a formidable problem and for this reason investigators have studied these two phenomena independently. In fact, there are very few systematic studies on E-C and the majority of references mention it only in passing. In most real systems, however, the two destructive processes take place simultaneously, hence the purpose of this paper is mainly to present the various interactions between the chemical and mechanical agents leading to accelerated degradation of the material. This review does nọt pretend to be exhaustive, racher the paperscited are those that lead to a better understanding of the process involved in the accelerated rate of material loss under $E-C$ conditions. 


\section{INTERACTION BETWEEN CHEMICAL AND MECHANICAL ATTACK}

The rate of metal loss in most corroding systems stifles itself due to the formation of a protective film. However, if this film is continuously removed or damaged, the stifling of the corrosion process may fail to occur. Thus, without special assumptions, it is expected that chemical and mechanical influences acting conjointly will produce far more damage than if acting separately. (Evans, 1960).

In a gaseous oxidizing atmosphere, a metal initially oxidizes rapidly to develop a protecitve oxide layer after which its rate of oxidation is negligible. If, however, the layer is removed or damaged, it starts to oxidize again at the initial rate and, if the mechanical damage is at sufficiently frequent intervals, the resultant material loss is barely distinguishable from the rate of material loss of the bare metal, Fig. 1. This is true not only of oxidizing atmospheres but all conditions where the protection is provided by the formation of surface protective film. Impact on a film-free metal surface is most likely to dent the surface. However, if the metal is covered by film, which lacks the ductility of the metal, the impact stress could crack the film and permit continued chemical action at the exposed area. In aqueous systems, the corrosion currents originating from locally exposea areas can be very large and lead to catastrophic failures, such as pitting and stress corrosion cracking. 
Hoar and Scully (1964). have shown that the deformation of metals by mechanical stressing could lead to an increase in the corrosion current. The local rise in temperature of the metals because of mechanical damage would also increase the rate of chemival action.

The mechanical properties of many materials can be affecter. by the presence of an aqueous or gaseous environment (Westwood and Stoloff, 1966; Davidson et al., 1976). If the environment produces an adherent surface film on the metal, the film will affect the yielding behavior of the metal and, hence, increase the strength of the metal. (Machlin, 1962; Westwood and Lye, 1968). However, non-adherent films, such as corrosive scales produced by hot corrosion, remove the strengthening provided by normal oxide films (Goebel and Pettit, 1970).

The process of film growth on bare material produces stresses and strains in the film. The initial stresses may be compressive, depending on the metal/metal-oxide system, and provide strengthening to the metal. Unfortunately, however, as the thickness of the film increases, the sign of the stress may change, i.e. become tensile, and lead to final cracking of the film (Cathcart, 1975).

Besides forming surface films, gaseous environments can affect the mechanical properties of materials by the diffusion of species from the gas phase into the bulk. For example, diffusion of carbon and nitrogen into the surface layer of the metal produces 
a case-harciened layer: The diffused species could also strengthen the material by segregation at dislocations (Price, 1966) or by forming precipitates, as in internal oxidation (Mahajan and Himmel, 1972). On the other hand, the segregation of hydrogen to form voids in the solid could cause hydrogen embrittlement (Thompson, 1976) or the precipitation of carbides and carbon could lead to catastrophic failure as in metal dusting (Perkins et al., 1976).

The aqueous medium can affect the mechanical properties by adsorption of surface-active species on the surface of the metal, such as liquid-metal embrittlement (Westwood et al., 197i) and Rebinder effects (Westwood and Lye, 1968). Macmillan and coworkers (1973) have established that the surface haraness of nonmetals is related to the zeta-potential of the solid. It is found that the hardness of the material is greatest when tine zetapotential is approximately zero. Thus, by changing the environment, the surface of the material can be made hard or ductile.

Active dissolution can have a strengthening effect on some materials: Joffé (1924) showed that salt crystals deformed in water were up to 25 times stronger and more ductile than those tested in air. The dissolution removes the existing notches and cracks on the surface of the crystal and thus increases the stress required for crack initiation in such brittle materials. The fatigue life of many netals can be improved by intermittent removal of deformed surface layers (Grosskreutz, 1971). Also, the rate of material loss of steel by cavitation is decreased by the 
application of an anodic current to the metal (Derendovski et al.., 1968). However, if the dissolution is selective or localized, it has a deleterious effect on the mechanical properties. Also, the local surface irregularity can cause turbulence in a flowing liquid and increase the intensity of mechanical attack at these local regiuns. Peterson and Gehring (1978) have shown that, as carbon steel specimens exposed to flowing sea water $(31 \mathrm{~m} / \mathrm{s})$ were roughened during the course of the run, cavitation bubbles were observed at the pits on the surface and this led to an increase in the rate of weight loss with time of exposure to the flowing water.

It is apparent from the examples presented above that interactions of environment and the material produce diverse and complex effects. It is, therefore, not always possible to quantitatively separate the chemical anci the mechanical effects. The interaction may be synergistic and lead to catastrophic failure, or one component may inhibit the harmful effect of the other. 


\section{AQUEOUS MEDIUM}

A. ELECTROCHE:ICAI CORROSION:

A large number of books (e.g. Uhlig, 1948; Fontana and Greene, 1967) have been written on aqueous corrosion, and, consequently, only the salient features relevant to E-C will be summarizeci in this section. Aqueous corrosion is electrochemical in nature and, therefore, the mechanisms of electrochemical reactions can be used to explain the rate of corrosion. Corrosion takes place by the formation of microcells, composed of jnodic and cathodic sites on the surface of the metal. Material is lost at the arode by the reaction:

$$
M \rightarrow M^{+}+e
$$

The simultaneous cathodic reaction is:

$$
2 \mathrm{H}^{+}+2 \mathrm{e} \rightarrow \mathrm{H}_{2}
$$

or

$$
\mathrm{O}_{2}+2 \mathrm{H}_{2} \mathrm{O}+4 \mathrm{e} \rightarrow 4 \mathrm{OH}^{-}
$$

Equation (2) is predominant in acidic solutions where there is a high concentration of hydrogen ions in the solution while Eq. i3) is prevalent in neutral or basic solutions. The rate of material loss is determined by the net currcat flowing through the circuit. The electrochemical reactions are limited by various physical and chemical factors, i.e. they are polarized. There are three types of polarizations; activation polarization, resistance polarization, and concentration polarization. Activation polarization refers to an electrochemical process which is controlled 
by the reaction sequence at the metal-electrolyte interface. Resistance polarization is a result of the electrical resistance of the electrolyte. The passage of the current through the electrolyte develops a voltage which reduces the driving force for the corrosion process.

Concentration polarization results when the reaction is controlled by the diffusion of a reactant, e.g. oxygen, through the electrolyte to the metal surface. Fig. 2 illustrates the path of ox ygen reaching the corroding metal. The oxygen has to cross the atmosphere-liquid interface (Laplace's layer), then through the bulk of the solution, and finally through the solution in the immediate vicinity of the sample, i.e. the diffusion layer (also known as Prandtl's layer), to the metal surface. The slowest step is the passage through the diffusion layer. The layer is relatively static, being kept in place by adsorption processes and, therefore, the oxygen car. pass by diffusion only. In the bulk solution oxygen can move not only by diffusion, but also by mechanical stirring, convection and thermal currents. Stirring can decrease the thickness of the dif Eusion layer and, thus increase the diffusion of oxygen through it.

The rate of metal ponetration is related not just to the total amount of current flow, wit to the anodic current density. Thus, for a given current, a small anode surrounded by a large cathode would give rise to a large localized metal loss at the anode, as in pitting. The unfavorable area ratio has the largest 
effect in galvanic or two-metal corrosion. When two dissimilar metals are in contact in an electrolyte, a potential dif:erence is generated between them. Generally, the metal with the more negative potential becomes anodic and corrodes, thus decreasing or eliminating the corrosion of the more positive metal. The driving force for galvanic corrosion is the potential difference between the two metals.

Potential differences can also be generated at different areas on the same metal by metal ion concentration cells or oxygen concentration cells. When a metal is in contact with a solution of its ions, the potential generated is the equilibrium between the tendency for the metal to go into solution and an opposing tendency for the ions to plate out on the metal. Thus, it foliows that the tendency of a metal to go in solution will be greater in a solution containing a low concentration of its ions than in that which the concentration of metal ions is greater. Similariy, it can be argued that the role of oxygen in the solution would be to reach an equilibrium by the corrosion reaction, Eq. (3). The regions having a high concentration of oxygen would be cathodic and tend to consume the oxygen by Eq. (3), while the regions low in oxygen would be anodic and, therefore, corrode.

Some metals and their alloys exhibit a loss of chemical reactivity under certain environmental conditions. This loss of reactivity is known as passivation. Passivation is caused by the formation of a protective surface film, probably an oxide film, on 
the metal surface. The nature and properties of protective films are very important from the standpoint of resistance to E-C. The ability of these films to protect the metal depends on the speed and ease with which they form when the metal is originally exposed to the environment, their resistance to mechanical damage, and their rate of reforming when destroyed or damaged. Iron, nickel, titanium, aluminum and their alloys which form passive oxide films are dependent on the avilability of oxygen to the surface for their corrosion protection. Therefore, conditions that increase the rate of diffusion of oxygen to the surface of these metals would aid the formation of the oxide and thus reduce the rate of metallic corrosion. In the case of active metals, such as copper, the increase in the diffusion of oxygen to the metal surface would increase the rate of metal loss by increasing the rate of Eq. (3).

Electrochemical techniques can be used to measure the rate of material loss due to corrosion (Baboin, 1977). Hieasurement of the electrode potential could determine the tendency of the metal towards corrosion, passivation, passive film cracking, and repassivation. Tafel extrapolation (Stern and Geary, 1957), and linear polarization (Mansfeld, 1976) are two techniques developed to measure the instantaneous corrosion rate. However, the age-old technique of immersing the metal in the aggressive environment and measuring its weight loss is still actively used. 


\section{B. EXPERIMENTAL TECHNIQUES :}

Most commonly used experimental techniques in aqueous $E-C$ studies can be divided into four categories, (1) flow through tests, (2) rotating sample tests, (3) jet tests, and (4) vibratory tests.

1. Flow Through Tests:

These tests are usually carried cut to simulate actual service conditions. Therefore, appropriate liquids are forced through pipes designed to duplicate flow conditions experienced in actual service. A section of the pipe at the location of interest or test specimen inserted in the flow is examined for its material loss. The test is used to simulate conditions in transportation of slurries, heat exchanger parts, distillation plants, etc. To study cavitation erosion a constriction in the form of a venturi is made in the pipe, and samples placed ahead of the venturi where the cavities collapse (Knapp et al., 1970).

2. Rotating Sample Tests:

In the rotating sample test a sample, in the shape of a drum, disc or flat plates attached at the periphery of a corrosion resistant disc, is axially mounted on a non-conducting spindle. The assembly is rotated about its axis in a tank of given electrolyte of interest. The rotating drum test is mainly used to do mechanistic studies of the effect of mass transport of corrosion species on $E-C$, since the flow characteristics of the liquid are relatively simple and easily controllea (Makridas, 1960). 
A metal disc is generall.y used to measure the effect of a range of velocities on a single sample. The velocity of the liquid across the surface of the metal varies from zero at the center of the disc to a maximum at the periphery. The test is simple and convenient and closely simulates the pattern of attack on propellers (LaQue, 1975). However, the flow characteristics of liquid around the disc are rather complex and not easy to analyze (Davis et al., 1977). In order to study the E-C of a large number of materials at coristant velocity, small plate samples are attached to a non-corroding disc. Since the length of the plate is much smaller than the disc, the range of velocities experienced by the sample is relatively small. Again this test is simple, but the flow of the liquid across the surface plate is more complex than over a disc (Syrett, 1976).

The rotating sample test can be modified to study cavitation erosion. Peripheral holes in the disc cause cavitation bubbles to trail from them and specimen buttons are located where the bubbles collapse (Iichtman and Weingram, 1964).

3. Jet Tests:

Generally for high velocity tests a multivelocity jet section is used. In this test a specimen is attached just upstream from a nozzle with an appropriate orifice plate. The size of the orifice determines the velocity of the liquid flowing over the coupon specimen. By arranging several jets in parallel, liquid from a single source can be fed on several specimens at different 
velocities sjmultaneously. The main advantage of the technique is that the velocity over the vample can be measured and controlled accurately (Danek, 1966). In addition, holes can be made in the test specimens to create cavitation effects in the flow (Knapp et al. , 1970).

To determine the $E-C$ of materials exposed to turbulent water at the entrance end of condenser tubes a jet impingement test has been Jeveloped (May and Stacpoole, 1950). This test consists of a liquid jet impinging on a stationary specimen, which is usually totally immersed in the same liquid. The flow characteristics of the Iiquid on the sample are much different from all the other tests. The water jet can be mixed with a given volume of air or other gases and the effect of bubble size on E-C can also be studied.

4. Vibrating Tests:

The most widely used device for accelerated cavitation erosion testing is the vibratory device. Cavitation is produced by an ultrasonic horn vibrating in stationary liquid. During the upward stroke, cavities form and grow in the low pressure region produced below the probe, while in the downward stroke, the pressure below the probe increases and the cavities collapse. The sample is attached at the tip of the vibratory horn or may be held stationary just below it. It has been argued that the test is too severe; metal loss is due to mechanical erosion alone. In order to demonstrate the contribution of corrosion in such tests, 
Plesset (1962) has modified the apparatus to provide cyclic interruption of vibration. The time of vibration and arrest is controlled to give the relative effect of corrosion and erosion on the total material loss.

The various testing tes.sniques were originally designed to screen the E-C resistance of a large number of materials to a given environmental condition and in this capacity the tests served well. However, it is difficult to compare the E-C resistance of the materials exposed to the different tests. The main difficulty is the different geometrits used in the various tests and the resulting complex flow characteristics experienced by the material. The problem could be partially eliminated by reporting results in dimensionless numbers, such as Reynold's number, Schmidt's number, etc. The use of dimensionless numbers would also lead to a better understanding of the effect of hydrodynamics on E-C. There is also an urgent need to standardize the various techniques.

In most tests the rate of attack is given as the weight loss for given time of exposure. Electrochemical techniques, listed in section III $A$, are now being used to obtain a better understanding of the corrosion processes in $E-C$. There is also an attempt to use electrochemical techniques in conjunction with weight loss measurements to determine the relative contribution of electrochemical corrosion and mechanical destruction (Davis, 1977; Macdonald et al., 1978) 


\section{EFFECT OF LIQUID VELOCIT?:}

In most cases of general corrosion, the flow of the liquid increases the rate of arrival of the corrosive species to the metal and the rate of removal of the corrosion product from the metal surface and, consequently, increases the rate of corrosion. However, if the metal forms a protective oxide film the increase in velocity will increase the availability of oxygen to the surface to form a passive film and, thus, decrease the rate of material loss. Therefore, it is necessary to know the exact exposure condition and the metal involved to determine the effect of velocity on the rate of material loss.

Danek (1966) exposed 53 alloys to flowing sea water up to $36 \mathrm{~m} / \mathrm{s}$ and categorized them for their E-C resistance. Alloys in the first group, titanium and nickel-chrome-high molybdenum alloys, exhibit high resistance to general corrosion and localized pitting at all velocities. Titanium forms a very tenacious film and has a fast rate of repassivation of the cracked film. These two properties are responsible for its good E-C resistance at all velocities. Stainless steels and most nickel alloys, that owe their corrosion resistance to the formation of protective passive films, fall into the second category and exhibit good E-C resistance at intermediate and high velocities. Oxygen is required to maintain a passive film and, therefore, a minimum velocity which supplies the required oxygen is recommended for these alloys in marine applications (Laque, 1975). In stagnant water, the accumulation 
of sand and corrosion products suffocate the regions under them of oxygen and cause the regions to be anodic. As the velocity of the liquid is increased, the sand and corrosion products would not be able to settle and the increased supply of oxygen would maintain a stable prctective film. However, these alloys could still corrode at the higher velocities in crevices due to insufficient oxygen supply in these regions. These alloys are also susceptible to differential oxygen cell corrosion, set up by differences in the local velocity of liquid on a metal. In rotating disc tests, stainless steel corrodes preferentially at areas close to the center than the periphery of the disc because of the formation of a differential oxygen cell (Copson, 1960; Vahdats and Newman, 1973).

Copper and its alloys fall into the third category, and have a Iundamentally differert response to flowing water. This is primarily because they do not form a classical passive film. However, the corrosion rate in stagnant water decreases parabolically due to the formation and growth of a corrosion product film on the surface (North and Pryor, 1976). The effect of velocity on the rate of corrosion is negligible up to a critical velocity, known as the breakaway velocity, after which the rate of material loss increases rapidly. On copper, oxygen acts as a depolarizer and an increase in the oxygen supply increases the corrosion rate. In a rotating disc test, the copper alloys corrode preferentially at the outer surface. The higher velocities 
at the periphery of the disc increase the supply of oxygen ard remove metal ions from the surface, thus setting up a metal ion concentration cell (Copson, 1960).

It is clear from the foregoing discussion that the rate of corrosion is controlled by the changes in the hydrodynamic boundary layer and the mass transport of various species through the electrolyte. The way in which the velocity changes the thickness of the hydrodynamic boundary layer is complex and depends on such factors as viscosity and temperature of the liquid, geometry of the equipment, the surface roughness of the metal, and whether the flow is laminar or turbulent (sherier, 1976). In the case of laminar flow, the thickness of the boundary layer is a well defined function of the velocity, while for turbulent flow the boundary layer is very thin and the flow of liquid toward and away from the metal surface is complex. Therefore, the rate of increase in corrosion with increase in velocity is different in the laminar flow than in turbulent flow. This has been demonstrated by cornet et al. (1961) for the corrosion of copper in flowing $2.1 \mathrm{~N} \mathrm{H}_{2} \mathrm{SO}_{4}$ for Reynolds number up to $10^{4}$.

The most successful application of hydrodynamic theory to date has been on metals dissolving under essentially film free condition, and the process is unambiguously controlled by the arrival of reactants to the metal surface, i.e. controlled by concentration overpotential. Processes controlled by concentration overpotential have a limiting diffusion current which 
imposes a maximum value on the corrosion rate. Since the limiting current is determined by the flow rate, it is possible to predict the changes in the corrosion rate if the relationship between the flow and concentration overpotential is known. Ross and Wragg (1965) and Ross et al. (1966) have developed a relationship between the limiting current $\left(i_{L}\right)$ and hydrodynamic parameter in pipes:

For laminar flow Re $<2000$,

$$
\frac{i_{L}}{2 F D \Delta_{a}}=1.64\left[(\operatorname{Re})(\mathrm{Sc}) \frac{\mathrm{d}}{\mathrm{I}}\right]^{0.33}
$$

for turbulent flow $2000<$ Re $<5000$

$$
\frac{i_{L}}{2 F D \Delta_{a}}=0.276(\mathrm{Re})^{0.58}\left[(\mathrm{Sc}) \frac{\mathrm{d}}{\mathrm{I}}\right]^{0.33}
$$

where, $D$ is the diffusion coefficient of reactive species; $\Delta_{a}$ is the activity difference between the surface and the bulk solution; $z$ is the charge number; $F$ is the faraday's constant; Re is the Reynold's number; $\mathrm{Sc}$ is the schmidt number; $d$ is the diameter of the pipe; and, $I$ is the length of the pipe.

The value of the limiting current can also be used for metals that passivate naturally. If the limiting current density of oxygen increases to a critical current required for passivation, then the increased flow leads to a marked decrease in the rate of metal dissolution. Vahdat and Newman (1973) have used such a relationship to explain the corrosion of iron rotating disc. Depending on the diameter and rotation speed of the disc, the periphery of disc 
is passivated (does not corrode) if the limiting current of the oxygen is reached, while the iron corrodes at the center of the disc.

Besides the enhanced mass transport, at high velocities the hydro-mechanical forces could be a major controlling factor in stripping away the corrosion product film and thus increasing the corrosion rate. Efird (1977) has given an expression for the surface shear stress $\left(\tau_{0}\right)$ :

$$
\tau_{0}=\frac{f \bar{v}^{2} p}{2}
$$

Knowing the average velocity $(\bar{v})$, density $(\rho)$, and friction factor (f) from the Reynolds number, the fluid shear stress ( 0 ) can be calculated. Efrid has used this expression to explain the breakaway velocity of a variety of copper alloys on the stability of their corrosion films.

A schematic plot of the material loss rate as a function of the Iiquid velocity or the surface shear stress for copper alloys is shown in Fig. 3 (Syrett, 1976). The figure has been split into 5 zones labeled A through $E$, each zone corresponding to a different erosion-corrosion process. In zone $A$, the flow is laminar, while in zone $B$, it is turbulent and the rate of metal loss is controlled by the transport of reactive species to the metal surface. The shear stress in these zones is not suficiently large to disrupt the film on the metal surface. At the breakaway velocity (i.e. at the onset of zone $C$ ), the shear stresses are so great that the film is removed in a few areas and severe corrosion takes place 
at the exposed areas. The metal loss is severe due to the galvanic currents flowing between the exposed metal and film covered areas. In zone $D$, the oxide removal is more general and therefore the contribution from galvanic currents is reduced, however, the rate of metal loss is high since a larger area of the bare metal is exposed to aggressive environment. In this zone, the degree of turbulence and the shear stresses are greatly increased and repassivation of the metal surface is difficult. zone E represents the velocity range where the film is completely removed and repassivation is not possible. It is also conceivable that at these high velocities the underlying metal may also be damaged. Although the curve has been dratrn to explain E-C of Copper alloys, the E-C processes discussed may be common to many metal systems. Also, depending on the alloy and environment, each zone may be narrower or wider than shown in the figure or one may be completely absent. Copper and its alloys are extensively used in flowing sea water since they are resistant to pitting and for their antifouling characteristics (Popplewell, 1978). Various attempts have been made to increase the $E-C$ resistance of these alloys, i.e. increase their breakaway velocity. Alloying copper with zinc, aluminum and nickel increases the breakaway velocity. Additions of small amounts of iron (0.4-0.7\%) to copper alloys containing 10-30\% nickel gives a further increase in the breakaway velocity. Verink and Lee (1972) have shown that iron 
improves the electrochemical properties of the copper-nickel alloys and improves the protectiveness of corrosion film. In recent years, it has been found that small additions of chromium to copper-nickel alloys alsn increases their E-C resistance. The addition of chromium causes a spontaneous spinoidal decomposition in these alloys; and hence, increase the mechanical strength of the alloy (Conde et al..1972). Two iron-chromium modified alloys IN-838 (Cu-18Ni-0.4Cr-0.8Fe-0.5Mn-0.3max C) and IN-848 (Cu-30Ni-0.4Cr-0.4max Fe-0.7Mn-0.03max C) have E-C rates that are one tenth of the respective base copper-nickel alloys in high velocity sea water.

Iiquid velocity also has a tremendous effect $c r_{4}$ jalvanic corrosion. Preiser (1969), Mansfeld and Kenkel (1977), and Davis and Gehring (1974) have shown that galvanic corrosion of aluminum coupled to copper, steel and titanium alloys increases with increase in velocity. Similarly, Ferkins and co-workers (1978) have reported an increase in corrosion rate of carbon steel in contact with copper alloys. Unfortunately, attempis at explaining these increases in terms of the changing eiectrochemical potential of the metals or the increased transport of oxygen have been unsuccessful. Therefore, Davis and Gehring (1974) have suggested that, at higher velocity, the erosion of the surface film and the metal may also contribute to the apparent increased rate of galvanic corrosion. 
D. LIQUID DROPS, JETS AND SLURRIES:

In the case of erosion-corrosion by liquid drops, jets and slurries all the accelerating effects of material loss due to the increased flow rate of the liquid, discussed in the preceding section, are operative. In addition, there is an effect of mechanical degradation by the impact event of the liquid or solid particles on the surface of the material. Shear stresses are also produced in the material due to the radial outflow of a Iiquid drop or jet (chapters 3 and 4) or the grazing of a solid particle on the surface of the material (chapters 1 and 2). However, the magnitude of the stress due to the radial flow c ver a smooth surface is very low in comparison to the impact stress (Rochester and Brunton, 1974) and, therefore, does not contribute to the erosion of materials. But, in a corrosive.environment, the radial shear stress may be sufficient to crack or remove the corrosion film and expose the fresh metal to the aggressive environment.

The most common type of $E-C$ by jets is observed at the entrance end of condenser tubes, and is known as impingement attack. The water entering the tubes may be turbulent and carry entrained air bubbles and this can cuase severe local attack of the tube material. The E-C is caused by the mechanical effects of the high velocity turbulent water and the impacting air bubbles (LaQue, 1975), and the depolarizing action of the oxygen present in the bubbles. The oxygen in the bubbles acts as a depolarizer 
and hence, increases the rate of E-C of active metals. In the case of passive metals the oxygen helps the retention of a protective film, and hence, decrease the rate of material loss. Here the rate of material loss is governed by the competition between the impact event, which breaks the film, and the oxygen in the bubble which repassivates it. The local material loss is accelerated by galvanic currents flowing between the impingement area (anode) and the unaffected area which is covered by an oxide film.

In sea water applications, the passive alloys, such as stainless steels, tend to undergo pitting corrosion which makes them unattractive for condenser tube applications despite their good resistance to high velocity turbulent waters. Hence, aluminum brasses and copper-nickel alloys are preferred for sea water exposure (Uhlig, 1972). In recent years, the new iron and chromium modified copper-nickel alloys have shown good resistance to impingement attack (Ferrara and Gudas, 1972). Titanium and titanium-base alloys resist both high velocity conditions and pitting corrosion, making them very useful for condenser tubes. This is especially true for condenser applications in the nuclear reactors where the leakage of copper ions in the water system has led to other forms of corrosion (Heaton, 1977).

In slurries, $i . e$. the suspension of solid particles in a liquid, the relative importance of mechanical and chemical components varies widely with the hydrodynamic intensity, fron 
purely mechanical damage at high velocities to mechanically accelerated corrosion at lower velocities, (Gandhi et al., 1975). In a study of the E-C of brass discs in 3\% NaCl solution, Saito (1972, 1973) found that the rate of corrosion of brass increases markedly when sand particles are added to the solution and the erosion rate increases with the increase in the slurry velocities from 1 to $7 \mathrm{~m} / \mathrm{sec}$. Up to a velocity of $3 \mathrm{~m} / \mathrm{sec}$ the brass could be protected cathodically, but at higher velocities cathodic protection was not sufficient. This suggests that, at low velocities of the slurry, the corrosion of the brass is the most important parameter in the metal loss while, at higher velocities, the abrasion of the brass by the sand plays a more significant role. Postlethwaite and co-workers (1974, 1975a, 1975b, 1976) studied the $E-C$ of steel pipes by slurries at low velocities (up to $4.5 \mathrm{~m} / \mathrm{s}$ ). They showed that the presence of hard abrasives, such as sand and iron ore, and soft particles, such as coal, increased the corrosion rate of the steel by a factor of ten. This large increase in the material loss could not be explained by the three most common effects of solid particles in flowing liqulc, namely (i) the solid particles cause local turbulence in the liquid, and, thus increase the rate of diffusion of oxygen to the metal surface, (ii) increases the rate of removal of the surface corrosion film, thus, exposing the bare metal to the environment, and (iii) the impacting particles roughen the surface of the metal, thus 
exposing a larger surface area to the corrosive environment. Therefore, the authors concluded that even at such low velocities, erosive process such as continuous removal of the protective film from the surface and yield assisted dissolution of the metal, play a significant role. It is quite possible, though, that mechanical removal of particles from the ridges of the rough surface could also contribute to the total weight loss.

The erosion of metals by slurries results from the dynamic action of the moving particles on metal surface. Depending on the flow conditions and the geometry of the system, the erosion can result from deformation of metal surface by the impact of solid particles, and eventual metal particle removal, or sliding, and hence, cutting wear. The rate of erosion will depend on the size and size distribution, concentrations, hardness, density, shape and composition of the solid particles. In general, the rate of erosion increases with increase in particle size and slurry velocity (Ghandi et al., 1975). However, the eifect of size distribution and concentration is more complicated. Wasp et al. (1971) have given an empirical relation for the concentration in a slurry pipeline.

$$
\log \frac{C}{C_{A}}=-1.8 \frac{W}{B K U} *
$$

where $C$ is concentration of solids at distance $0.42 \mathrm{D}$ from the center of the pipe; $D$ is the diameter of the pipe; $C_{\mathrm{A}}$ is the concentration of solids at the center of the pipe; $w$ is the 
settling velocity of the solid in the slurry; $B$ is the ratio of momentum transfer coefficient to the mass transfer coefficient; $K$ is the von Karman constant, and $U^{*}$ the friction velocity is given by the ratio of the wall shear stress to the slurry density .

If the $C / C_{A}$ ratio is $<0.2$, the erosion rate increases with increase in slurry concentration. When the $C / C_{A}$ ratio of the maximum size particle in the slurry is $>0.2$ the erosion by the particles is negligible prov ded the velocity of the flow is less than $3 \mathrm{~m} / \mathrm{s}$. Therefore, since the value of $\mathrm{C} / \mathrm{C}_{\mathrm{A}}$ also increases with increase in total concentration of solids, the erosion rate will first increase with increase in concentration, reach a maximum at $\mathrm{C} / \mathrm{C}_{\mathrm{A}} \simeq 0.2$ and then decrease with further increase in concentration. This criterion applies only when the velocity of the slurry is above the critical deposition velocity. In long term tests, the rate of material loss by slurries decreases as a function of time. Posthethwaite et al. (1978) observed that rate of material loss of steel pipes decreased from $4 \mathrm{~mm} / \mathrm{yr}$ to $2 \mathrm{~mm} / \mathrm{yr}$ after $300 \mathrm{~h}$ of exposure to a slurry of sand in water. On changing the sand in the slurry, hovever, there was an increase in the rate of material loss. rhus, suggesting a change in the characteristics of the sand particles. The erosion process could smoothen the sand particles and decrease the size distribution of the particles. The E-C changes the surface characteristics of metal, i.e: cover it by a film 
and harden the base metal, and this could also lead to a decrease in the rate of material loss.

E. CAVITATION :

The loss of material by the repeated formation and collapse of cavities in a liquid at localized regions of low pressures is known as cavitation, and has been discussed in detail in Chapter 5 and 6 . When the phenomenon of cavitation erosion was first discovered, there was a controversy on the mechanism of material loss; whether it is predominantly electrochemical or totally mechanical. Krenn (1949), Petracchi (1948), Wheeler (1956) and Taylor (1960) emphasized the electrochemical nature of the material loss. However, theoretical calculations of the stress produced by a single bubble e.g. (Rayleigh, 1917; Schulmeister, 1965) and experimental measurement of the stress produced by a cloud by cavities (Vyas and Preece, 1977) show that the mechanical effects of cavitation are easily large enough to plastically deform a ductile metal or crack a brittle material. Moreover Plesset (1970) has shown that materials can be destroyed in relatively inert Iiquids.

It is today realized that cavitation damage can be explained as a result of the combined actions of mechanical and chemical factors (Eisenberg et al., 1965; Pecknev, 1959, Preiser and Tytell, 1961; Plesset, 1960; Timerbulator, 1969; Pokhmurskii et al., 1974; Leith and Thomson, 1960). For instance, Glikman (1962) has shown that the material loss of most alloys is higher 
in sea water (more corrosive environment) than in fresh water at the same cavitation intensity. The elusive elements in developing a satisfactory mechanism has been the relative degree that mechanical and electrochemical agents contribute to the total material loss and their mutual interaction and synergistic effects.

Cavitation produces chemical changes in the environment which can aid the process of electrochemical corrosion. The speed of the chemical reaction can be increased by (I) local streaming of the liquid around a cavity, (2) diffusion of dissolved gases into the cavity, and (3) production of reactive species in the electrolyte.

Using a photugraphic plate under an ultrasonic probe Nyborg et al. (1959) have shown that there is an increased darkening of the plate around a single resonating bubble on the plate due to microstreaming of the liquid around it. This effect is illustrated schematically in Fig. $4 a$. In the case of a cioud of bubbles produced by an ultrasonic horn, there is microstreaming at the edge of the ultrasonic horn as shown in Fig. 4b. In addition to microstreaming, alternating pressure pulses under the ultrasonic horn, macroscopic hydrodynamic flow due to the increased turbulence, and thermal hydrodynamic flow can increase the rate of arrival of reactive species to the surface. 
Lindstrom (1955) studied the effect of aissolved cas content in the liquid on the chemical effects of ultrasonic cavitation. He showed that most of the dissolved gases in the liquid are incorporated into the cavities in the first few minutes of cavitation. The gas can then be evolved out of the liquid by the large bubbles or chemically react with the metal surface.

Weissler (1953), Lindstrom (1955) and El'piner :1959)

have reviewed the chemical effects of ultrasonic cavitation and found them to be similar to radiation chemistry. At very low intensities of ultrasound, where no cavitation is present, there is no chemical change. However, at a critical intensity of ultrasound, that is at the inception of cavitation bubbies, $\mathrm{H}_{2} \mathrm{O}_{2}$ is produced and the yield $\mathrm{H}_{2} \mathrm{O}_{2}$ is proportional to the dissolved oxygen in the liquid and the intensity of cavitation. El'piner and Sokol'skaya (1960) have shown that bivalent iron is oxidized to trivalent iron when a solution of $0.01 \mathrm{~N} \mathrm{FeSO}_{4}$ in $1.1 \mathrm{~N}$ $\mathrm{H}_{2} \mathrm{O}_{4}$ is subjected to ultrasonic cavitation. This oxidation reaction is facilitated by the presence of oxygen, decreased by hydrogen and completely eliminated by the presence of helium in the solution. Using internal friction measurements, Gina and Messino (1969) hare shown that tantalum specimens exposed to ultrasonic cavitation in water pick up hydrogen atoms presumably produced by the breakup of the water molecules. These chemical effects of cavitation are not only limited to ultrasonic cavitation, 
but have also been observed in a venturi and in hydraulic machinery, (El'piner, 1959; Hobbs et al., 1971).

A large number of electrochemical measurements have been carried out on metals exposed to vibratory cavitation to determine the role of corrosion in cavitation E-C. Altof and co-workers $(1973,1973 a)$ have shown that the potential of copper alloys in oxygenated $1 \mathrm{~N} \mathrm{NaCl}$ solution shifts in the negative direction upon the application of a cavitation field. Cavitation also increases the corrosion current of copper at all potentials, in water and ferrous chloride solution (Hirth and speckhardt, 1972). The shift in potential and increase in corrosion current is attributed to the removal of the corrosion product film by the imploding cavities.

On passive alloys, such as titanium, aluminum and iron alloys, in deoxygenated $1 \mathrm{~N} \mathrm{NaCl}$ solution and high intensity of cavitation there is a large negative shift in potential (e.g. for $A I, \Delta V^{n},-500 \mathrm{mV}$; for $\left.T i, \Delta V^{n}-900 \mathrm{mV}\right)$. However, in oxygenated solutions the potential shift is much smaller (Altof and coworkers 1973b, 1974, 1975). Engleberg and Yahalom (1972) have observed an increase in passivation current of iron in $3 \circ \mathrm{NaCl}$ solution in a cavitaticn fic -d, and Preece and Vyas (1974) have shown that the passivation current of nickel in $1 \mathrm{~N} \mathrm{H}_{2} \mathrm{SO}_{4}$ increases with increase in cavitation intensity. The large negative shift in potential in deoxygenated solution is due to the cracking of the passive film and exposing the film-free metal to the solution. 
In oxygenated solutions, the small shift in potential and the increase in corrosion current is a result of the competition between the destruction of the passive film by cavitation and the rate of repassivation of the exposed film-free metal. This effect is exemplified in Fig. 5, where a polished $\mathrm{Ni}$ sample was held at a passive potential of $+600 \mathrm{mV}$ for $0.5 \mathrm{in}$ (current density $=0.01 \mathrm{~mA} / \mathrm{cm}^{2}$ ) and subsequently subjected to cavitation. Under cavitation the current rose to $0.42 \mathrm{~mA} / \mathrm{cm}^{2}$ in the first $20 \mathrm{~min}$ and then rose sharply to $1.8 \mathrm{~mA} / \mathrm{cm}^{2}$ and finally reached a "steady" value of $n 1.0 \mathrm{~mA} / \mathrm{cm}^{2}$. The sharp rise in current is accompanied by a weight loss signifying film cracking and corrosion at localized film-free areas. The final "steady" current denotes a new equilibrium between the film cracking and repassivation kinetics.

On the other hand, titanium and aluminum alloys that were initially active (not passivated) in the solution quickly reached a passive potential (Altof et al., 1973b, 1974). A similar positive shift in potential has been observed for titanium and 18-8 stainless steel by vyas (1975). The chemical effects of cavitation, such as the coalesence of dissolved oxygen into the cavitating bubble and the production $\mathrm{H}_{2} \mathrm{O}_{2}$ could explain the spontaneous passivation of these alloys.

Corrosion has an effect on morphology of the surface damage and rate of mechanical erosion by cavitation. Preece and vyas (1974) and Deredovski et al. (1968) found that mechanical weight 
loss (i.e. the total weight loss less that fraction due to the corrosion current) of nickel and steel respectively decreases upon the application of an anodic current. By residual stress measurements, the latter investigators found that the mechanical damage produced in the surface layer by the cavitation was much less when an anodic current was applied to the metal. Thus, it appears, that the mechanically stressed layers may have been continuously removed by the applied current, thereby exposing fresh, unworked metal to the cavitation cloud. On the other hand, Hirth and Speckhardt (1972) observed an increase in the mechanical weight loss of copper upon the application of an anodic current. However, they observed that the cavitation induced undulations on the surface of the metal were shallow and broader under these conditions. This was attributed to the preferential dissolution of the ridges of the undulations. The damage on passive metals titanium, aluminum and iron (Altof et al.. 1973b, 1974; and Engleberg and Yahalom, 1972) is non-uniformly distributed on the surface due to the local cracking of the film and accelerated corrosion of the exposed area. Also, Beeching (1942) has reported that localized corrosion, especially pitting, increases the mechanical erosion since the irregular surface aids the formation of cavities in the pits.

Cathodic protection has been successfully used to decrease the rate of material loss by cavitation erosion (Eisenberg et al., 1965; Preiser and Tytell, 1961; Plesset, 1960). However, cathodic 
protection works only when hydrogen bubbles are evolved Erom the sample under the cavitation field. At low cathodic potentials, where no hydrogen is evolved, there is no appreciable decrease in the erosion rate. The decrease in the material loss rate is not only due to the absence of anodic dissolution of the metal, but also due to the decrease in the collapse pressure of the bubbles due to the cushioning effect of the hydrogen gas on the cavity collapse (Plesset, 1960). 


\section{GASEOUS MEDIUM}

\section{A. OXIDATION}

Oxidation (Evans, 1960, 1968, 1976, Wood, 1970a) by gaseous oxygen is not just a chemical union of the metal and oxygen ions, but an electrochemical process similar to aqueous corrosion. However, during oxidation the growing oxide film serves simultaneously as an electrolyte for ionic and electronic migration and an electrode for oxygen reduction. The most important conseguence of this phenomenon is the decrease in the rate of oxidation as the thickness of the film increases (if the film is adherent to the metal surface). oxidation of a metal takes place in several stages, (1) the oxygen atoms adsorbed on the metal surface form oxide nuclei at localized regions, (2), the oxide ruclei grow laterally to form a continuous film on the metil surface (3) the continuous oxide film increases in thickness (Ouder, 1976; Rapp, 1976). The thickening of the film occurs by the movement of oxygen from the uxide/gas interface inward, or the migration of the metal cations from the metal/oxide interface outward. Since the rate of migration is generally proportional to the thickness of the film, the rate of oxidation obeys a parabolic law. The oxidation of most base metals, such as iron, nickel, chromium and cobalt is controlled by the outward migration of metal cations. This outward migration can lead to a vacancy condensation at the metal/oxide interface and, hence, decrease the adherence of the film to the metal surface. 
When an alloy containing several components is exposed to an oxidizing atmos shere at elevated temperatures, the first formed oxide probably comprises nuclei of all oxide phases in proportion to their alloying content. As the alloy surface becomes covered, the oxygen activity at the metal/oxide interface decreases to a value (determined by the dissociation pressure of the oxide present) where only the most thermodynamicaliy stable oxides can grow. Thereafter the oxidation rate is controlled by the kinetics of diffusion of the least noble component from the bulk alloy to the metal/ozide interface and the rate of oxygen diffusion into the alloy. The oxygen diffusion rate, in turn, defends on the dissociation pressure of the adherent scale and the rate of transport of alloying elements outward through the oxide. Wood (1970b) has male a review of the possible morpholojies of the oxide in binary alloy systems.

Geierally, chromium and aluminum are added to increase the high temperature oxidation resistance of most industrial alloys since they form continuous protective films on the surface. However, the preferential oxidation of chromium in Fe-ivi-cr alloys depletes the material underneath of dissolved chromium, and if the oxide film were removed by erosion, the depleted metal would corrode at a much faster rate.

B. CORROSION BY COMPLEX GASES

In most industrial situations, such as the chemical and petroleum industry, coal conversion plants and gas turbines, a 
large variety of metals and alloys are exposed to complex gas mixtures containing oxygen, carbon $\left(\mathrm{CO}, \mathrm{CO}_{2}, \mathrm{CH}_{4}\right)$, sulfur $\left(\mathrm{H}_{2} \mathrm{~S}\right.$, $\mathrm{SO}_{2}$ ) and hydrogen $\left(\mathrm{H}_{2} \mathrm{O}\right)$. To determine the corrosion resistance of the alloy, it is necessary to know first the oxidizing, carburizing and sulfidizing potential of the gas mixture and, second, the relative thermodynamic stability of the various metal oxides, sulphides and carbides at these potentials (Perkins and Coons, 1977). The problem is further complicated by the presence of chemically reactive solid particles (ash and salt) and the change in composition of gas by the reaction of the gas with the metal surface. Therefore, it is difficult to evaluate the resistance of ali materials to complex gas corrosion or to determine the variety of chemical reaction possible in these environments. This section describes some of the most important corrosion reactions.

1. Accelerated Oxidation:

Birks (1976) has reviewed the effect of $\mathrm{H}_{2} \mathrm{O}, \mathrm{CO}_{2}$ and $\mathrm{SO}_{2}$ in the gas on the rate of oxidation of metals. In an oxidizing atmosphere all three components increase the rate of oxidation by the physical transport of the gaseous species through the scales to the metal surface and various chemical reactions at sites within the oxide scale which favor the transport of oxygen through the scale. Fig. 6 shows possible reactions within the scale due to the presence of $\mathrm{H}_{2} \mathrm{O}$ and $\mathrm{CO}_{2}$ in the atmosphere. The hydrogen in the scale produces interstitial protons and ion 
vacancies which increase the ionic transport of oxygen ions through the scale. Similarly, the formation of co at the pores and deposition of carbon increase the rate of oxidation in $\mathrm{CO}_{2}$ containing gases.

In $\mathrm{SO}_{2}$ containing gases the metal may exhibit enhanced oxidation or form sulphides depending on the partiai pressure of oxygen or sulphur in the gas mixture. The partial pressure of sulphur is given by the equation:

$$
\begin{array}{r}
1 / 2 \mathrm{~S}_{2}+\mathrm{O}_{2} \rightleftarrows \mathrm{SO}_{2} \\
\mathrm{P}_{\mathrm{S}_{2}}=\mathrm{K}\left[\frac{\mathrm{P}_{\mathrm{SO}_{2}}}{\mathrm{P}_{\mathrm{O}_{2}}}\right]
\end{array}
$$

where $\mathrm{K}$ is the equilibrium constant for the reaction. Thus, increasing the $\mathrm{O}_{2}$ partial pressure decreases the rate of metal attack by sulphidation at the metal surface. However, the enhanced oxidation and the transport of sulphur through the oxide to the metal surface would increase the local partial pressure of sulphur at the metal/oxide interface, and, thus form sulphides at this interface. Sulphides have low melting points and form eutectics with the oxide, for example Fe-FeS, Feo-Fes and Fe-FeoFes eutectic mixtures melt at 988,940 and $925 \mathrm{C}$ respectively. Since the diffusion of oxygen in the liquid phase is very rapid, the presence of the liquid phase significantly increases the rate of metal oxidation. 
2. Sulfidation

Sulfidation (Mrowec, 1976), that is the formation of sulphide scales, not only occurs in $\mathrm{SO}_{2}$ atmospheres (as discussed above) but also in reducing atmospheres of $\mathrm{H}_{2} \mathrm{~S} / \mathrm{H}_{2}$ mixtures. Farber and Ehrenberg (1952) have studied sulfidation in $\mathrm{H}_{2} \mathrm{~S} / \mathrm{H}_{2}$ mixtures and found that an increase in the chromium content in the alloy decreases the rate of corrosion due to sulphidation. Adaition of aluminum to the alloy has also been found to be beneficial for protection against sulfidation (Zalenko and Simkovich, 1974). Solid sulfide films are brittle and less protective and could, therefore, be easily removed in an erosive environment.

3. Hot Corrosion

Accelerated corrosion in sulphur containing oxidizing gases and alkali metal salts is known as hot corrosion. Hot corrosion is dependent on the formation of liquid alkali salts, $\mathrm{Na}_{2} \mathrm{SO}_{4}$ and $\mathrm{K}_{2} \mathrm{SO}_{4}$, which dissolve the protective oxide films and allow the metal to form non-protective oxide films (Goebel et al., 1974). The ingestion of vanadium oxide, vanadium (Bornstein et al., 1975), chlorides (Shores, et al., 1976), and, free carbon (Mckee and Romeo, 1974) into the gas environment enhances the rate of hot corrosion. In general, additions of aluminum and chromium to an alloy increases its resistance to hot corrosion.

4. Carburization

Carbon from carbonaceous atmospheres, such as $\mathrm{CO}, \mathrm{CO}_{2}, \mathrm{CH}_{4}$, can be transferred into the metal and, when the saturation 
concentration of the carbon in the metal is exceeded, carbides are precipitated in the metal. This process is known as carburizetion (Hochman, 1976) and has two detrimental effects (a) the most stable carbide formed is $\mathrm{Cr}_{23} \mathrm{C}_{6}$, and, therefore, the alloy matrix is depleted of chromium and (b) it occurs at localized regions, such as crevices, grain boundaries, etc. and, thus, decreases the mechanical properties of the metal. Carburizaiion can also lead to a phenomenon called metal dusting: the localized pitting of iron and nickel base alloy exposed to carbonaceous atmospheres in the temperature range of $400-350^{\circ} \mathrm{C}$. Hochman (1976) and Perkins, et al. (1976) have shown that metal dusting is caused by the formation of an unstable carbide which spontaneously transforms to free carbon and the metal. This reaction is autocatalytic and leads to localized deterioration of the alloy.

c. EFFECT OF GAS FLOW

The rate of oxidation of most metals and alloys is much greater in flowing gases than in stagnant atmospheres (Evans, 1960) due to the increased rate of arrival of the oxidizing species to the metal surface. The effect is most significant in flowing complex gas mixtures, especially in systems in which rate controlling step of oxidation is at the oxide/gas interface (Birks, 1976). One important consequence of the increase in the oxidation rate is to form thick oxide scales on the metal. As the film thickness increases, tensile stresses are generated in the film and this leads to film cracking and eventual spalling of the film (Cathcart, 1975). 
Aerodynamics of the gas flow can also influence the partial pressures of the various components in the complex gas. For instance, the flow of the gas could shift the equilibrium of Eq. (8) to the right or the left and, thus, cause enhanced oxidation or sulfidation of the metal. Therefore, the gas flow not only increases the rate of the reaction, but also changes the type and structure of the reaction product. Local fluctuations in the gas velocity can lead to two different corrosion processes to occur on the same metal. For example, in carbonaceous atmospheres, it has been observed that carburization takes place in crevices and sharp bends in the pipelines, where the flow of the gas is restricted, while the rest of the metal exhibits enhanced oxidation (Perkins et al., 1976).

High velocity gas flow (> $100 \mathrm{~m} / \mathrm{s}$ in turbines) can generate large shear and/or normal stresses on the metal (depending on the angle of gas flow with respect to the metal surface). The high stress is capable of removing loosely adherent surface films and exposing the bare metal to the aggressive environment by the mechanism given in Fig. 1. The shear stresses can spread out liquid corrosion products such as metal sulphides or remove them as Iiquid drops and deposit them at other locations on the sample. Such a phenomenon has been known to increase the rate of hot corrosion (Condë, 1974). Also, Weigand (1945) has shown that, above a certain gas pressure, metal loss in flue gases occurs by local melting and erosion of the metal by aerodynamic forces. 
chemical and mechanical forces of flowing gases increases the material loss of $\mathrm{X}-45(\mathrm{CO}-10.5 \mathrm{Ni}-25.5 \mathrm{Cr}-7.5 \mathrm{~W}-0.25 \mathrm{C})$ and $\mathrm{U}-500$ (Ni-19Co-19Cr-4Mo-3Ti-4Fe-0.1C) alloy in flue gas at $980 \mathrm{C}$ from $5 \mathrm{mg} / \mathrm{cm}^{2}$ in stagnant atmosohere to $20 \mathrm{mg} / \mathrm{cm}^{2}$ in gases flowing at $150 \mathrm{~m} / \mathrm{s}$. Moller (1973) has predicted that gas stream velccity in turbines at $750 \mathrm{C}$ gives a threefold increase in rate of metal loss of Nimonic $80 \mathrm{~A}$ (Ni-20Cr-5maxFe-2maxCo-2.5Ti-1.2A1-0.1max C). Alkidas et al. $(1976,1977)$ have studied the E-C of AISI 4340 steel in pressurized gases $\left(\mathrm{O}_{2}, \mathrm{H}_{2}, \mathrm{CO}_{2}, \mathrm{CO}\right.$ and $\left.\mathrm{N}_{2}\right)$ at $3000^{\circ} \mathrm{K}$ and found that material loss is greatest in oxygen containing gases. Optical microscopy confirm that the erosion is caused by the removal of low shear strength oxide scales produced by the oxygen in the gas.

In order to obtain a better understanding of the effect of aerodynamics in turbines on the rate of $\mathrm{E}-\mathrm{C}$, Moore and Crane (1973) have reviewed the possible mechanisms of deposition of combustion products and injested material on the turbine blades and its relation to $E-C$. The major mechanisms of deposition are (1) inertial impaction, (2) diffusion from laminar boundary layer, (3) diffusion from turbulent boundary layer and (4) eddy impact. Large particles can deviate from the gas streamlines and deposit on the blade surface by inertial forces, while smaller particles can only diffuse through the gas boundary layer on to the metal surface. The rate of diffusion in laminar fiow is dependent on 
the diffusion coefficient of the particles and the concentration difference across the boundary layer, while in turbulent gases, the rate of diffusion is further enhanced by Brownian motion. Particles that are tos large to cross the region of low turbulence due to Brownian motion can impact the blade surface by partial response to the eddies in turbulent flow. Although these theories would give a quantitative evaluation of the rate of arrival of particulate matter to the metal surface, the authors emphasize that the final rate of metal loss of the blade may be very much influenced by: (i) the ability of the particles to attach to the metal surface, (ii) temperature fluctuations on the blade. surface, (iii) the coagulation of particles in the gas stream and (iv) the deposition rate in the off-design condition of the turbine.

spenglar et al. (1977) have used a similar approach to model the particulate flow in gas turbines and predict the frequency, angle of impact and the velocity distribution of the impacting particles on the turbine blade surface. Figure 7 shows the particle trajectories in the gas turbine first stage. Furthermore, they have extended their analysis to predict the variation of metal loss along the axial distance of a turbine blade for different size ash particles, Fig. 8. D. SOLID PARTICLE EROSION

It has generally been recognized that erosion by solid particles can accelerate the rate of material loss in a high temperature corrosive atmosphere. For example, Nateson (1976) 
and Perkins and Coons (1977) have recognized the importance of erosive process in coal conversion plants. Mahorter (1974) and Shaw (1974) have shown that erosion by sand and salt can have a significant effect on the deterioration of engines and turbines used in marine applications. It has been argued that the high rates of hot corrosion in marine environments can only be explained by the cracking of the oxide film by the impact of salt particles (Restall, 1974). Also, the corrosion product particles torn off from the surface of the metal and entering the gas stream to impact on another location can cause serious damage of the metal. However, in spite of the importance of the problem, very few investigations have been done to determine the mechanism of solid particle erosion in a corroding system.

The rate of erosion of a metal at room temperature depends on a large number of variables, such as the size, concentration and velocity of particles, their physical and mechanical properties, the angle of impact, and the mechanical properties of the target metal, as described in chapters 1 and 2. In a high temperature corrosive environment, the temperature, the various corrosion reactions and the resultant change in the surface of the metal become added variables. All these variables are interdependent and comprise to form a complex experimental situation. Therefore, the study of $E-C$ in such environments have been generaliy limited to an evaluation of a particular metal in a given industrial environment, and only a few investigators have attempted to cbtain a better 
understanding of solid particle E-C.

Tilly (1969) and Semeltzer et al. (1967) have exposed a series of super alloys, low carbon steel, stainless steels, cupper alloys, titanium alloy and aluminum to solid particles erosion up to $600 \mathrm{C}$ and found a decrease in the rate of material loss with an increase in temperature. This has been attributed to an increase in ductility of the material at the higher temperature. However, thesn investigators did not take the high temperature oxidation of the materials into account. On the other hand, Ives (1977) reported a tenfold increase in the rate of crosion of Type 310 stainless steel at $975 \mathrm{C}$ compared to the erosion at $25 \mathrm{C}$ when exposed to a corrosive combustion gas atmosphere.

Young and Ruff (1977) have shown that the erosion rate of a material at the higher temperatures may increase or decrease depending on other variables, such as the angle of impact, the particle size and the type of solid particle. They observed that the maximum in the rate of erosion of Type 304 stainless steel at $500 \mathrm{C}$ occurs at an impact angle of $10^{\circ}$ versus $20^{\circ}$ at $25 \mathrm{C}$. This is attributed to an increase in the ductility of the metal at $500 \mathrm{C}$. However, a second weak maximum is observed at an impact angle of $90^{\circ}$ and this is explained by the formation of a thick oxide scale on the surface of the metal at the higher temperature. The oxide scale behaves in a brittle manner and the interaction of the solid particles with the brittle scale 
could lead to a high rate of erosion at normal incidence. They also exposed a large number of stainless steels to $50 \mathrm{um}$ and $5 \mathrm{um}$ alumina particles at an impact angle of $45^{\circ}$ and found that while there is no appreciable change in the erosion rate between 25 and $500 \mathrm{C}$ for the $50 \mathrm{~m}$ alumina particles, there is a fifteenfold decrease in the case of impact by the $5 u \mathrm{~m}$ particles. Furthermore, on considering different types of solid particles, they find that the decrease in the erosion rate is larger for the softer particles (e.g. pumice) than the harder particles such as silica and alumina. All these observations suggest that the rate of material loss is dependent on the interaction of the solid particles with the growing surface oxide film on the metal at the higher temperature.

Scanning electron microscopy observations of the damaged surface give further evidence of interaction of the corrosion film with the erosion process. Ives (1977) and Young and Ruff (1977) have observed cracked oxide films on surfaces impacted at high temperatures as against a general rumpling of the surface at low temperatures. Goeble et al. (1977) have confirmed the existence of exide films on metals exposed to high temperature E-C conditions by electrical conductivity measurements across the eroded surface. They observed a very thin oxide film $(<1 u m)$ on the surface of a variety of turbine materials impacted by $20 \mu \mathrm{m} \mathrm{Al}_{2} \mathrm{O}_{3}$ particles, while the oxide film on the surface impacted by the $2 \mu \mathrm{m}$ particles depends on the angle of 
impact: at an impact angle of $90^{\circ}$, a thin layer of oxide is fcrmed, but, at an impact angle of $45^{\circ}$ the film is much thicker. The surface topography of the turbine alloys eroded with $20 \mu \mathrm{m}$ alumina particles at $870 \mathrm{C}$ are similar to those observed for the erosion of ductile metals at low temperature: at nearly normal impact angles surface depressions similar to those made by a hardness indenter are observed whereas at the lower impact angles groove-like depressions are produced. Also, a very thin oxide is observed under the eroded surface compared to a thick oxide present on the erosion free surface. These observations led Geobel et al. (1977) to propose that under these conditions the oxide scale which develops between subsequent impacts is very thin and probably does not effect the erosion process. On the other hand, samples impacted by $2 \mu m$ alumina particles exhibit a very irregular surface with a thick, but cracked oxide film. Therefore, there is greater interaction between the oxidation and erosion process for the smaller particles.

Based on these observations, Goebel et al. (1977) have proposed that the rate of erosion may be dependent on the relative size of the particle and the thickness of the protective oxide, as shown schematically in Fig. 9. When the thickness of the film is small compared to the average diameter of the impacting particle, the particles break through the oxide layer and deform the substrate. The thin oxide layer has a negligible effect and the erosion occurs by the interaction between the particle and the 
substrate. If the thickness of the oxide film and the average diameter of the film are comparable, the erosion process woid involve the cracking and eventual spalling of the oxide film as well as some deformation of the substrate metal. Under these conditions the oxide film would have a significant efrect on the erosion process.

The erosion rate is also dependent on the type of oxide scale formed on the alloy. Mikhailova et al. (1975) exposed three alloys, 20Kh25N20S2 (Fe-25Cr-19.5Ni-0.09C-2.4Si-0.76Si); KhN45Yu (Fe-15.25Cr-45.5Ni-3.37Al-0.06C-0.2Si-0.5Mn); Khr 60VT (Ni-25.6Cr$15.2 \mathrm{~W}-2.4 \mathrm{Fe}-0.52 \mathrm{Ti}-0.08 \mathrm{C}-0.48 \mathrm{Si}-0.45 \mathrm{Mn})$ to fluidized corundum particles in fume $\left(3 \frac{\circ}{5} \mathrm{CO}_{2}, 15 \% \mathrm{O}_{2}\right.$, rest $\left.\mathrm{N}_{2}\right)$ gases at 900-1000 C. The 20Kh25N2052 and KhN45Ya are high temperature oxidation resistant alloys, forming $\mathrm{Cr}_{2} \mathrm{O}_{3}, \mathrm{FeO}-\mathrm{Cr}_{2} \mathrm{O}_{3}$ and $\mathrm{Al}_{2} \mathrm{O}_{3},(\mathrm{Fe}, \mathrm{Ni})$ o- $\mathrm{Cr}_{2} \mathrm{O}_{3}$ protective films respectively. The $\mathrm{KNN} 60 \mathrm{VT}$ is a good erosion resistant alloy at room temperature but, poor corrosion resistance. The E-C resistance, in the high temperature fluidized bed, is higher for $\mathrm{Al}_{2} \mathrm{O}_{3}$ film forming $\mathrm{KLN} 45 \mathrm{Yu}$, than the $\mathrm{Cr}_{2} \mathrm{O}_{3}$ film forming 20Kh25N2052. The erosion resistant alloy KLli60VT has the poorest $E-C$ resistance. The order is similar to their resistance to oxidation in the aggresive atmosphere without the solid particles. Also, Goebel et al. (1977) found that, among various superalloys, the Co, Cr, AlY alloys (Co-25Cr $6 \mathrm{Al}-0.2 \mathrm{Y}$ and $\mathrm{Co}-17 \mathrm{CO}-12 \mathrm{~A} 1-0.5 \mathrm{Y})$, that form $\mathrm{Al}_{2} \mathrm{O}_{3}$ scales, perform better under E-C conditions in a turbine than the alloys that 
form $\mathrm{Cr}_{2} \mathrm{O}_{3}$ scales.

E. SURFACE FILMS

It is clear from the discussion in the last section the rate of material loss in E-C conditions is governed by the presence of a surface film which acts as a barrier between the aggressive environment and the base alloy. Considerable effort has been directed towards understanding the kinetics of the formation and growth of this film and its effect on corrosion. However, the mechanical properties of the film, which has received relatively little attention, would be of greater importance under E-C conditions and its understanding lead to the design of materials which are more resistant to E-C. This section summarizes the causes of stress generation in surface film and the methods of relaxation of the stress to maintain a protective film throughout the engineering life of the material. Stresses are generated in films due to (1) the volume ratio of the metal and the oxide; (2) epitaxial relation between the metal and the oxide; (3) changes in composition of the oxide; (4) specimen geometry; and (5) external means, such as thermal cycling and mechanical stressing (Springer, 1970; Hancock and Hurst, 1976; Cathcart, 1975).

Pilling and Bedworth (1923) showed that, if the ratio of the volume of the oxide to the volume of the metal is not unity, stresses are generated at the metal/oxide interface. In metals such sodium, potassium, calcium, which have a ratio less than 
unity, tensile stresses are generated and these oxides crack continually, leading to a linear rate of oxidation. Most industrial alioys have a volume ratio greater than unity and this gives rise to compressive stresses in the scales which, therefore, are generally protective. At the initial stages of oxidation, the differences in the lattices of the metal and the oxide generate epitaxial stresses; however, as the oxide scale grows, the epitaxial constraints are removed and other factors become more important.

Changes in the composition of the oxide or the metal during film growtin produce stresses in the film. In addition, oxidation in compiex gases and the incorporation of carbon, sulphur or hydrogen in solution in the oxide or diffusion of carbon or oxygen in the bulk metals produce stresses in the oxide film. The precipitation of carbides at grain boundaries produces a wedge effect in the metal, while the transformation of unstable carbide to metal and carbon during metal dusting can cause the oxide to "explode" (Hockman, 1976). The depletion of chromium in Fe-Cr-Ni alloys during oxidation causes the depleted metal to contract and this generates large stresses at the metal/oxide interrace.

One of the most important parameters producing stresses in a film is the specimen geometry. Stresses generated on a flat surface are much less than on a curved surface and for this reason cracks are first observed on the edges of the sample during oxidation. The sign and magnitude of the stress on a 
curved surface depend on the mechanism of oxidation, i.e. by either cationic or anionic migration and the curvature of the sample (Hancock and Hurst, 1976).

External stresses produced by thermal cycling and mechanical loads add to the stresses produced by the oxidation process, and the mechanical stability of the film is determined by the sign and magnitude of the total stress.

The total stress in the oxide can be relaxed by one of these four mechanisms: (I) film cracking; (2) detachment at the metal/ oxide interface, (3) deformation of the oxide, and (4) deformation of the substrate metal. The first two catagories are the most undesirable modes of stress relief. Recently, however, it has been shown that additions of $\mathrm{Y}, \mathrm{Sc}$, La and rare earth metals to the alloy decreases the oxidation rate and improves the adhesion of the oxide to the metal (Tien and Pettit, 1972).

The third category, deformation of the oxide, could be used as a constructive criteria for stress relief. However, very little is known about the mechanical properties of the oxide films. Studies on bulk oxides show that they do not possess the five independent slip systems required for ductility and, hence, tend to be brittle under load at low temperatures. At high temperatures, the oxides exhibit considerable ductility under compressive loads, but almost no ductility under tensile loads (Evans and Langdon, 1976). However, the mechanical properties of the surface films may be quite different from those of bulk oxides. 
Consequently, the most fruitful approach to decrease the stresses in the oxide film would be to allow the substrate to deform. Presently, the philosophy of the design of high temperature alloys is to add elements to farm an oxide film for corrosion protection and increase the strength of the substrate to sustain the mechanical load. Hancock and Hurst (1976) have suggested that it would be worthwhile to reduce the strength of the substrate which would facilitate its deformation and, hence, maintain the integrity of the oxide film. In fact, the selective oxidation of chromium and aluminum denude the substrate alloy of these elements, and does reduce the strength of the denuded zone facilitating the deformation of this zone. 


\section{SUMMARY AND RECOMMENDATIONS FOR FUTURE WORK}

Although it is recognized that the conjoint action of chemical and mechanical factors generally increases the rate of material loss in most industrial situations, our understanding of the processes involved in the conjoint action is far from complete. This is true, not only for the type of E-C discussed in this chapter, but, for other forms of conjoint action, such as, stress corrosion cracking, corrosion fatigue and frettage.

The interaction of chemical and mechanical modes of attack produce diverse and complex forms of material degradation. Also, the study of $E-C$ involves the consideration of 2 large number of interdependent variables, which forms an extremely difficult experimental situation. Therefore, at the present time, it is not possible to develop a complete theory of any given type of E-C. However, it does seem appropriate to list important points common to all the types of E-C corrosion discussed in this paper:

1) Surface films: the structure (oxide, passive or corrosion product film), kinetics (e.g. rate of repassivation) and the mechanical properties of protective surface film have a large effect on the rate of $E-C$.

2) Fluid mechanics: the type of flow of the fluid (laminar or turbulent), not only controls the rate of mass transport of 
corrosive and erosive species towards and away from the solid surface, but, at high velocities can generate surface shear stresses large enough to disrupt the protective film exposing the bare metal to the aggressive environment.

3) Impact event: the jmpact by the erosive agent (liquid drop, jet, cavity collapse or solid particle) not only deforms the solid and leads to eventual material loss, but, can easily crack the generally more brittle surface film and cause accelerated corrosion at the local exposed areas.

While there are many approaches possible to gain further insight into processes involved in $E-C$, what is required most are carefully designed experiments of well characterized systems providing results which can be easily analyzed. Some of the topics which merit further wurk are listed below:

1) The study of the structure and the kinetics of growth of surface films, especially if any changes are produced in structure and kinetics of a film which is being continually impacted.

2) Determination of the mechanical properties of surface films, their resistance to both normal and shear stresses and their adhesion to the base metal. Information gained in 1 and 2 would not only allow the engineer to develop alloys with better surface films, but, also help him develop better coatings for $\mathrm{E}-\mathrm{C}$ resistance. 
3) Mechanistic study on the effect of the fluid flow on the rate of mass transport of species to and from the solid surface and its relation to the rate of E-C. Such studies have been initiated and modes of mass transport determined, however, considerably more information is required to obtain quantitative relations between fluid flow and the rate of $\mathrm{E}-\mathrm{C}$. It is also necessary to consider quantitatively how solid particles in a slurry or cavities in a pipe effect the type of flow (e.g. from laminar to turbulent) and, hence, the rate of mass transport.

4) Experiments should be designed such that all fluid flow parameters can be described by dimensionless numbers. The use of dimensionless numbers would allow easy comparison of results from test done in different geometries.

5) Obtain quantitative value for the surface shear stress produced by high velocity flow.

6) Electrochemical techniques, listed in section IIIC, should be used in conjunction with weight loss measurements to separate the relative contribution of erosion and corrosion in E-C. 
VI ACKNOWLEDGMENT

This work was partially supported by the Department of Energy, Contract \# EY-76-C-02-0016. 


\section{REF ERENCES}

Alkidas, A.C., CavenY, L.H., Sommerfield, M., and Johnson, J.W. (1976). In "Properties of High Temperature Alloys" (Z.A. Foroulis and F.S. Pettit, eds.) p. 199, The Electrochemical Society, New Jersey.

Alkidas, A.C., Christoe, C.W., Caveny, I.H., and Summerfield, M. (1977). J. Engineering Materials and Technology, Trans ASME, 99, 239.

Altof, von F.C., Buhl, H., and Voight, H. (1973). Werkstoffe und Korrosion, 24, 606 .

Altof, von F.C., Buhl, H., and Voight, H. (1973a). Werkstoffe und Korrosion, 24,673 .

Altof, von F.C., Buhl, H., and Voight, H. (1.973b). Werkstoffe und Korrosion, 24,1020 .

Altof, von F.C., Buhl, H., and Voight, H. (1974). Werkstoffe und Korrosion, 25, 1 .

Altof, von F.C., Buhl, H., and Voight, H. (1975). Werkstoffe und Korrosion, 26, 682 .

Baboin, R., ed. (1977). "Electrochemical Techniques for Corrosion" NACE, Houston, Texas. 
Beeching, R. (1942). Trans. Inst. Eng. and Shipbuilders Scotland, 85,210

Birks, N. (1976). In "Properties of High Temperature Alloys" (Foroulis, Z.A. and Pettit, F.S., eds.) P. 215, The Electrochemical society, New Jersey.

Bornstein, N., and DeCrescente, M. (1975). "Proceedings of Gas Turbine Materials in the Marine Environment Conference" (J.W. Fairbanks and I. Machin, eds.) MCIC-75-27, p. 115.

Cathcart, J.V., ed. (1975). "Stress Effects and the oxidation of Metals," AIME, New York.

Condé, J.F.G., Booth, G.C., Rowlands, J.C., and Angell, B. (1972). Proc. Third Int. Congr. Marine Corr. and Fouling, 299.

Condé, J.F.G. (1975). In "Proceedings of Gas Turbine Materials In Marine Environment" (J.W. Fairbanks and I. Machlin, eds.) MCIC-75-27, p. 73 .

Copson, H.R. (1960). Corrosion, 16, 86 t.

Cornet, I., Barrington, E.A., and Behrsing, G.U. (1961). J. ElectroChem. Soc., 108, 947 .

Danek, Jr., G.J. (1966). Naval Engineers J., 78, 763. 
Davidson, J.M., Aning, K., and Tien, J.K. (1976). In "Properties of High Temperature Alloys" (Z.A. Foroulis and F.S. Pettit, eds.) p. 175, The Electrochemical Society, New Jersey.

Davis, J.A., and Gehring, Jr., G.A. (1974). Paper No. 78, Corrosion/74, NACE, Chicago, Illinois.

Davis, J.A., ed. (1977). Paper No. 101, Corrosion/77, NACE, San Francisco, California.

Derendovski, A.F., Bologa, M.K., and Shal'nev, K.K. (1968). Dok. Akad. Nauk. SSSR, 183, 1292 .

Efird, K.D. (1977). Corrosion, 33, 3 .

Eisenberg, P., Preiser, H.S., and Thiruvengerdam, A. (1965).

Society of Naval Architects and Marine Engineers - Transactions,

73, 241 .

El'piner, I.E. (1959). Sov. Phys. Acoust., 5, 135.

El'piner, I.E., and Solok'skaya, A.V. (1960). Sov. Phy. Doklady, $\underline{4}, 1393$.

Engleberg, G., and Yahalom, J. (1972) - Corrosion Science, 12, 469 .

Evans, A.G., and Langdon, T.G. (1976). Progress in Material

Science, 12, No. 3-4. 
Evans, U.R. (1960). "The Corrosion and Oxidation of Metals," Edward Arnold Ltd., London.

Evans, U.R. (1968). "The Corrosion and Oxidation of Metals," lst Supplementary Volume, Edward Arnold Ltd., London.

Evans, U.R., (1976). "The Corrosion and Oxidation of Metals," 2nd Supplementary Volume, Edward Arnold Ltd,, London.

Farber, M., and Ehrenberg, D.M. (1952). J. Electrochem. Soc., 99, 427 .

Ferrara, R.J., and Gudas, J.P. (1972). Proc. Third Int. Congr. Marine Corr. and Fouling, 285.

Fontana, M.G., and Greene, N.D. (1967). "Corrosion Engineering," McGraw Hill Book Co., New York.

Gandhi, R.I., Ricks, B.L., and Aude, T.C. (1975). Ist Int. Conf. Internal and External protection of Pipes, Sept. 9-11, University of Durham.

Gina, P.E., and Messino, C.D. (1969). Letteri al Nuovo Cimento, 1 , 305.

Glikman, L.A. (1962). "Corrosion - Mechanical Strength of Metals," Butterworths, London.

Goebel, J.A., and Pettit, F.S. (1970). Met. Trans., 1, 1943. 
Goebel, J.A., Felten, E.J., and Pettit, F.S. (1974). In "Corrosion Problems in Energy Conversion and Generation," (C.s. Tedmon ed.l p. 79, The Electrochemical Society, New Jersey. Goebel, J.A., Spriggs, D.R., Barkalow, R.H., and Pettit, F.S., (1977). Paper No. 53, Corrosion/77, NACE, Sar Erancisco, Cal. Grosskreutz, J.C. (1971). Phys. Stat. Sol. (b), 47, 11 . Hancuck, P., and Hurst, R.C. (1976). In "Advances in Corrosion Science and Technology," (M.G. Fontana and R.w. Staehle, eds.) Vol. 4, p. 1, Plenum Press, New York.

Heaton, W.E. (1977). British Corr. J., 12, 15.

Hirth, Von F.W., and Speckhardt, H. (1972). Werkstoffe und Korrosion, 23, 1.112 .

Hoar, T.P., and Sculiy, J.C. (1964). J. Electrochem. Soc., Ill, 348 .

Hobbs, J.M., ana Rachman, D. (1971). Trans. Inst. Of Eng. and Shipbuilders in Scotland, paper No. 1357.

Hochman, R.F. (1976) . In "Properties of High Temperature Alloys" (2.A. Foroulis and F.S. Pettit, eds.) p. 715, The Electrochemical Society, New Jersey.

Humpherys, J. (1973). Trans. Inst. Met. Finishing, 51, 204. 
Ives, I.K. (1977). J. Engineering Materials \& Technology, Trans ASME, $99,126$.

Joffe, A., Kirpitschewa, M.W., and Lewitsky, K.A. (1924). ‥ Physik, 22, 286.

Knapp, R.T., Daily, J.W., and Hammitt, F.G., (1970). "Cavitation," MCGraw Hill, New York.

Krenn, H. (1949). Electric Reviews, 545.

La Que, F.I. (1975). "Marine Corrosion." John Wiley and Sons, New York.

Lee, S., Decorso, S., and Young, W. (1970). ASME paper 70-WA/CD 2. Leith, W.C., and Thompson, A.L. (1960). J. Basic Eng., Trans ASME, 32, 795 .

Lichtman, J.z., and Weingram, E.R. (1964). Symp. on Cavitation Research Facilities and Techniques, ASME, 185.

Lindstrom, D. (1955). J.Acoustical Soc. of Am., 27, 654 . Macdonald, D.D., Syrett, B.C., and wing, S.S. (1978). Paper No. 25, Corrosion/78, NACE, Houston, Texas.

Machlin, E.S. (1962). In "Strengthening Mechanisms in Solids," p. 375, ASM, Cleveland, Ohio. 
Macmillan, N.H., Huntington, R.D., and Westwood, A.R.C. (1973). M.M.L. Technical Report 73-1lc.

Mahajan, S., and Himmel, L. (1972). Acta Met., 20, 1319.

Makridas, A.C. (1960). J. Electrochem. Soc., 107, 869.

Mansfeld, F. (1976). In "Advances in Corrosicn Science and Technology" (M.G. Fontana and R.w. Staehle, eds.) Vol. 6, p. 163, Plenum Press, New York.

Mansfeld, F., and Kenkel, J.V. (1977). Paper No. 100, Corrosion/ 77, NACE, San Francisco, California.

May, R., and Stacpoole, R.W. (1950). J. Inst. Metals, 77, 331.

McKee, D.W., and Romeo, G. (1974). In "Corrosion Problems in Energy Conversion and Generation." (C.S. Tedmon Jr., ed.) 118. The Electrochemical Society, New Jersey.

Mikhailova, N.A., Kop'eva, O.M., Kozlova, N.N., Bogolybskii, S.D., Frolava, R.F., Brun-Tsekhovoi, A.R., Il'enko B.K., Stadnik, V.F., and Lyapunov, A.I. (1975). Zashchita Metallov, 11, 641.

Moller, W. (1973). In "Deposition and Corrosion in Gas Turbines," (A.B. Hart, and A.J.B. Cutler, eds.) p. 1, John wiley and Sons, New York. 
Moore, M.J., and Crane, R.J., (1973). In "Deposition and Corrosion in Gas Turbines," (A.B. Hart and A.J.B. Cutler, eds.) p. 34, John wiley and Soris, New York. Mrowec, S. (1976). In "Properties of High T'emperature Alloys" (2.A. Foroulis and F.S. Pettit, eds.) p. 413, The Electrochemical Society, New Jersey.

Natesan, K., (1976). Corrosion, 32, 364.

North, R.F., and Pryor, M.J. (1970). Corrosion Science, 10, 297. Nyborg, W.I., Gould, R.k., and Jackson, F.J., Adams, C.E. (1959). J. Acoust. Soc. An., 31, 706 .

Oudar, J. (1976). In "Properties of High Temperature Alloys" ( $\mathrm{z}$. A. Foroulis and F.S. Pettit, eds.) p. 61, The Electrochemical Society, New Jersey.

Peckner, D. (1959). Corrosion, 15, 269 t.

Perkins, R.A., Coons, W.C., and Radd, F.J. (1976). In "Properties of High Temperature Alloys;" (2.A. Foroulis and F.S. Pettit eds.) p. 733, The Electrochemical Society, New Jersey.

Perkins, R.A., and Coons, W.C. (1977). Paper No. 49, Corrosion/77 NACE, San Francisco, California. 
Perkins, J., Graham, K.J., Storm, G., Locke, J., and Cummings, J.R. (1978). Paper No. 26, Corrosion/78, NACE, Houston, Texas. Peterson, M.H. and Gehring, Jr., G.A. (1978), Paper No. 28, Corrosion/78, NACE, Houston, Texas.

Petracchi, G., (1949). La Metallurgia Italiana, 41, I.

Pilling, N.B., and Bedworth, R.E. (1923). J. Inst. Metals, 29, 529.

Plesset, M.S. (1960). J.Basic Engg., Trans ASME, 82, 808 . Plesset, M.S. (1962) . Corrosion, 18, 5. Plesset, M.S. (1970). J. Basic Engg., Trans ASME, 92D, 807. Pokhmurskii, V.I., Tolstova, S.V., Milyakov, A.P., and Korotushenko, G.V. (1974). Eiz. Khim. Mekh. Mat., 10, No. 6, 22. Popplewel1, J.M. (1978). Paper No. 21, Corrosion/78, NACE, Houston, Texas.

Postlethwaite, J., Tinker, E.D.B., and Hawrylak, M.W. (1974). Corrosion, 30,285 .

Postlethwaite, J. and Hawrylak, M.W. (1975). Corrosion, 31, 237. Preiser, H.S. and Tytell, B.H. (1961). Corrosion, 17, $535 t$. Preiser, H.S. (1969). Technical Report 338, Hydronautics Inc. Laurel, Maryland. 
Preece, C.M., and Vyas, B. (1974). 4th Int. Conf. Rain Erosion and Allied Phenomenon (A.A. Fyall and R.B. King, eds.) Royal Aircraft Establishment, U.K., 811.

Price, C.E., (1966). Acta Met., 14, 1781.

Rapp, R.A. (1976). In "Properties of High Temperature Alloys" (A.z. Foroulis and F.S. Pettit, eds.) p. 77, The Electrochemical Society, New Jersey.

Rayleigh, Lord (1917). Phil. Mag., 34, 94 .

Rochester, M.C., and Brunton, J.H. (1974). Proc.4th Int. Conf. Rain Erosion and Allied Phenomenon. (A.A. Fyall, and R.B. King, eds.), Royal Aircraft Establishment, U.K., 371.

Ross, T.K., and Wragg, A.A. (1965). Electrochim. Acta, 10, 1093.

Ross, T.K., Wood, G.C., and Mahmud, I. (1966) . J. Electrochem. Soc., 113, 334 .

Russel1, T., and Kiuchi, J.T. (1978). Paper No. 13, Corrosion/78, NACE, Houston, Texas.

Saito, A., Shinego, E., and Kumagai, T. (1972) .. Corrosion Technology, 21, 120 .

Saito, A., Shinego, H., and Kumagai, T. (1973). Corrosion Technology, 22, 441 . 
Schulmeister, R. (1965). Proc. Ist Int. Conf. Rain Erosion and Allied Phenomenon (A.A. Fyall, ed.), Royal Aircraft Establishment U.K., 95.

Shores, D.A., Mickee, D.W., and Spacil, H.S. (1976). In "Properties of High Temperature Alloys." (A.z. Foroulis and F.s. Pettit, eds.) p. 349, The Electrochemical Society, New Jersey.

Shreir, L.I. (1976). "Corrosion," Vol. 1, 2nd edition, NewnesButterworths, London.

Smeltzer, C.E., Gulden, M.E., and Compoton, W.A. (1970). J. Basic Eng., Trans ASME, 92, 639 .

Spengler, C.J., Sverdrup, E.F., Lee, S.Y., Menguturk, M., Ulke, A., and Oriel1, E. (1977). Paper No. 13, Corrosion/77, NACE, San Francisco, California.

Springer, J. (1970). Corrosion Science 10, 513.

Stern, M., and Geary, A.L., (1957). J. Electrochem. Soc., 104, 56.

syrett, B.C. (1976). Corrosion, 32, 242 .

Taylor, I. (1960). Discussion of paper by W.H. Wheeler, Trans $\underline{\text { ASME }}, \underline{82 \mathrm{D}}, 184$. 
Thompson, A.W. (1976). In "Effect of Hydrogen on Behavior of Materials," (A.W. Thompson, and I.M. Bernstein, eds.) p. 467, AIME, New York.

Tilly, G.P. (1969). Wear, 14, 63.

Timerbulator, M.G. (1969), Fiz. Khim. Mekh. Mat., 5, No. Z, $5 n$.

Uhlig, H.H. (1948). "Corrosion Handbook," John Wiley and Sons, New York.

Uhlig, H.H. (1972). Proc. Third Int. Congr, Marine Corr. and Fouling, 234 .

Vahdat, N., and Newman, J. (1973). J. Electrochem. Soc., 120, 1682.

Verink, Jr., E.D., and Lee, T.S. (1972). Proc. Third Int. Congr. Marine Corr. and Fouling, 241.

Vyas, B. (1975). Ph.D. Thesis, SUNY, Stony Brook, New York.

Vyas, B., and Preece, C.M. (1976). J.Applied Physics, 47, 5133.

Wasp, E.J., Aude, T.C., Seiter, R.H., and Thompson, T.L. (1971). In "Advances in Solid Liquid Flow in Pipes and its Application." (I. Zandi, ed.), Pergamon Press, Oxford, New York.

Weigand, J.H. (1945). BRL Report No. 520, Ballistic Research Lab., Aberdeen Proving Ground, Maryland. 
Weissler, A. (1953). J.Acoustical Soc. of Am., 25, 651 .

Westwood, A.R.C., and Stoloff, N.S., eds. (1966). "Environment Sensitive Mechanical Behavior," Gordon and Breach, New York.

Westwood, A.R.C., and Iye, R.G. (1968). In "Surfaces and Interfaces," Vol. II, 3, Syracuse University Press, Syracuse, New York.

Westwood, A.R.C., Preece, C.M., and Kamdar, M.H. (1971). Eracture, Vol. $3,589-643$.

Wheeler, W.H. (1956). "Cavitation in Hydrodynamics," H.M.S.O., London.

Wood, G.C., "Oxidation of Metals and Alloys," ASM, Metals Park, Ohio (1970).

Wood, G.C. (1970a), Oxidation of Metals, 2, 11.

Young, J.P., and Ruff, A.W. (1977) . J. of Eng. Mat. \& Tech.,

Trans. ASME, 99, 121 . 


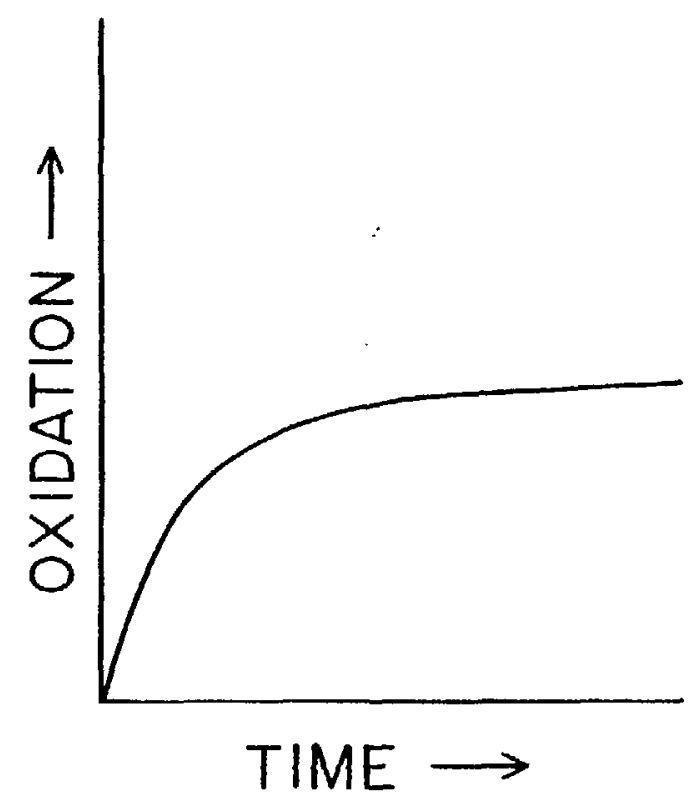

(a)

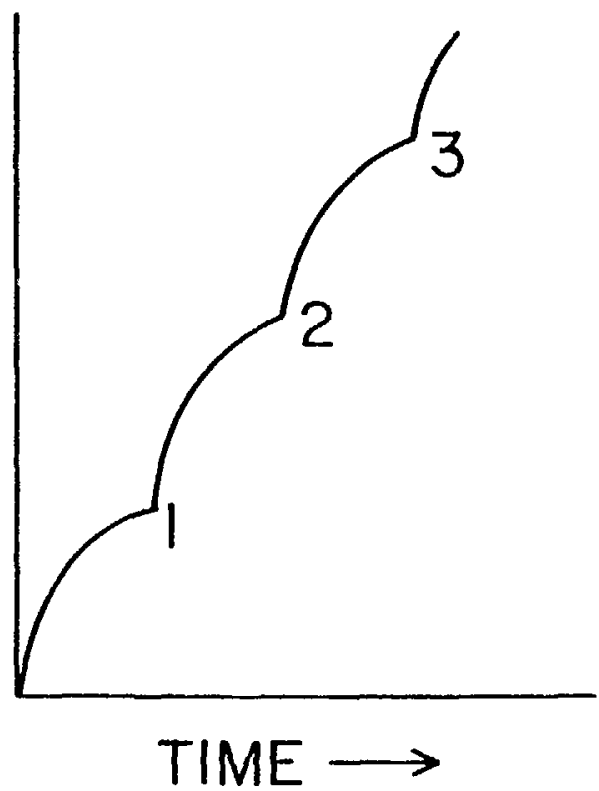

(b)

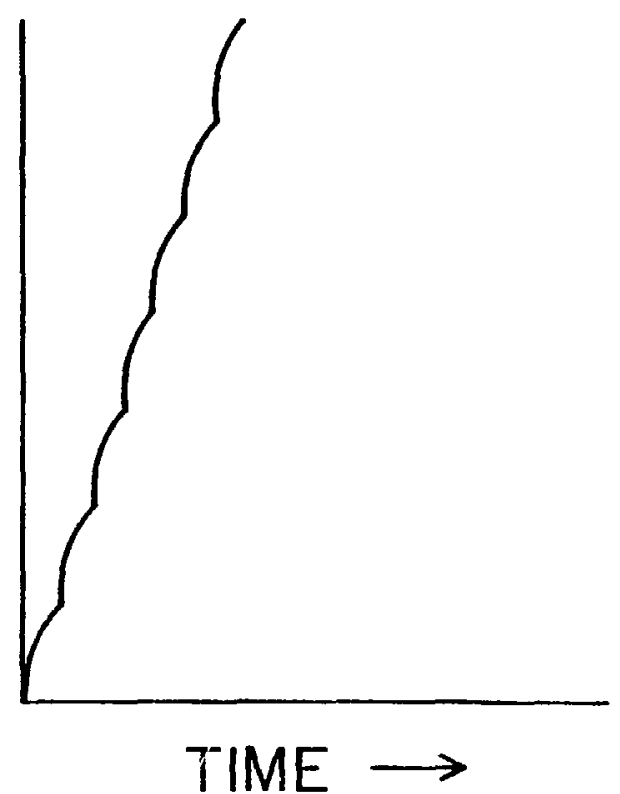

(c)

ligure 1. Oxidation versus tilluz of exposure (a) non film growth; (b), :ilm broken at 1,2 and 3;

(c) film broken frequently, producing a linear rate of oxidation (Evans, 1960). 


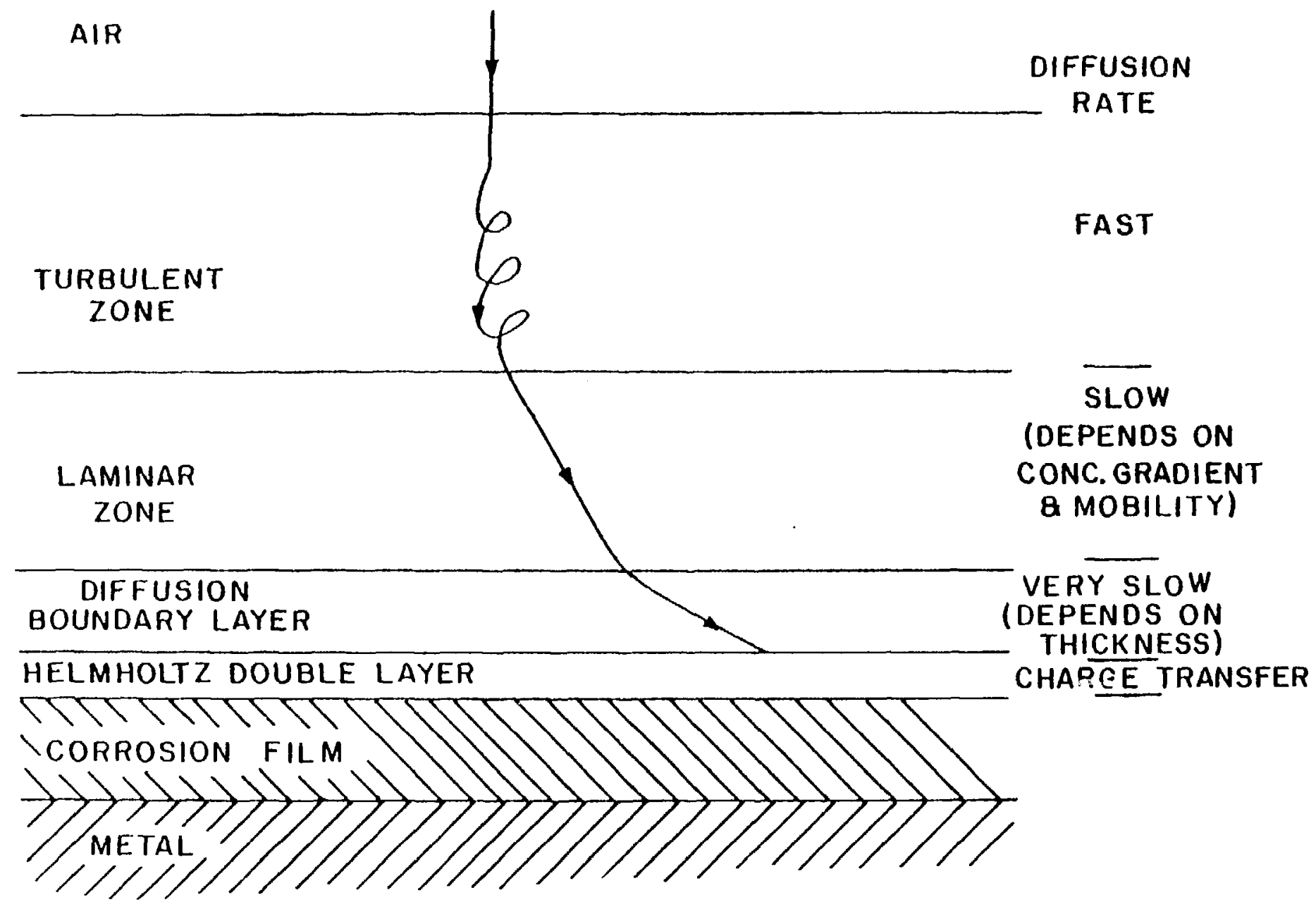

Flourl 2. Schematic of diffusion of oxygen to the metal surface through a flowing liquid. 


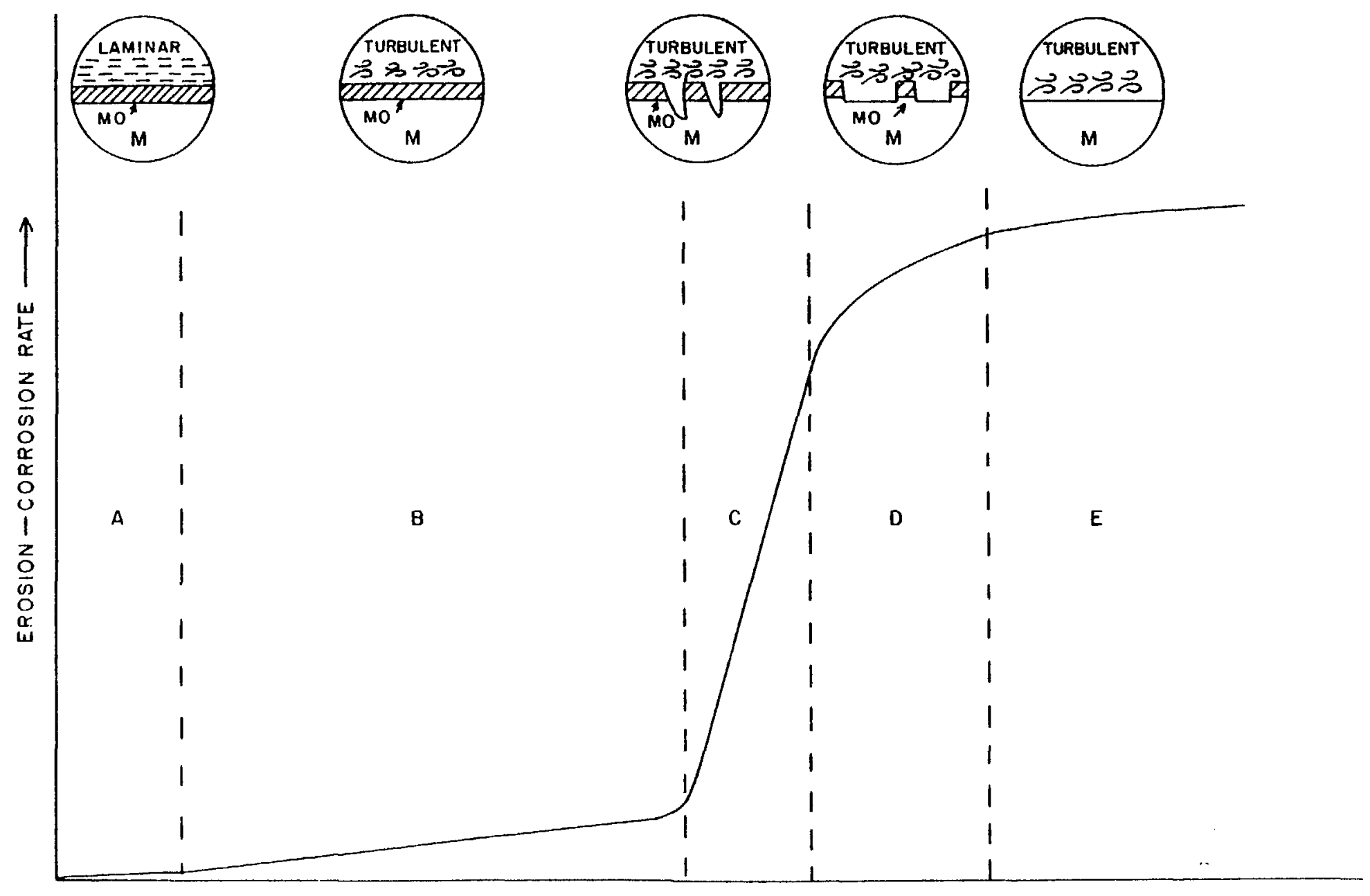

VELOCITY OR SHEAR STRESS $\longrightarrow$

PIGURE 3. Changes in erosion-corrosion mechanism as a function of velocity of the liquid (syrett, 1976). 

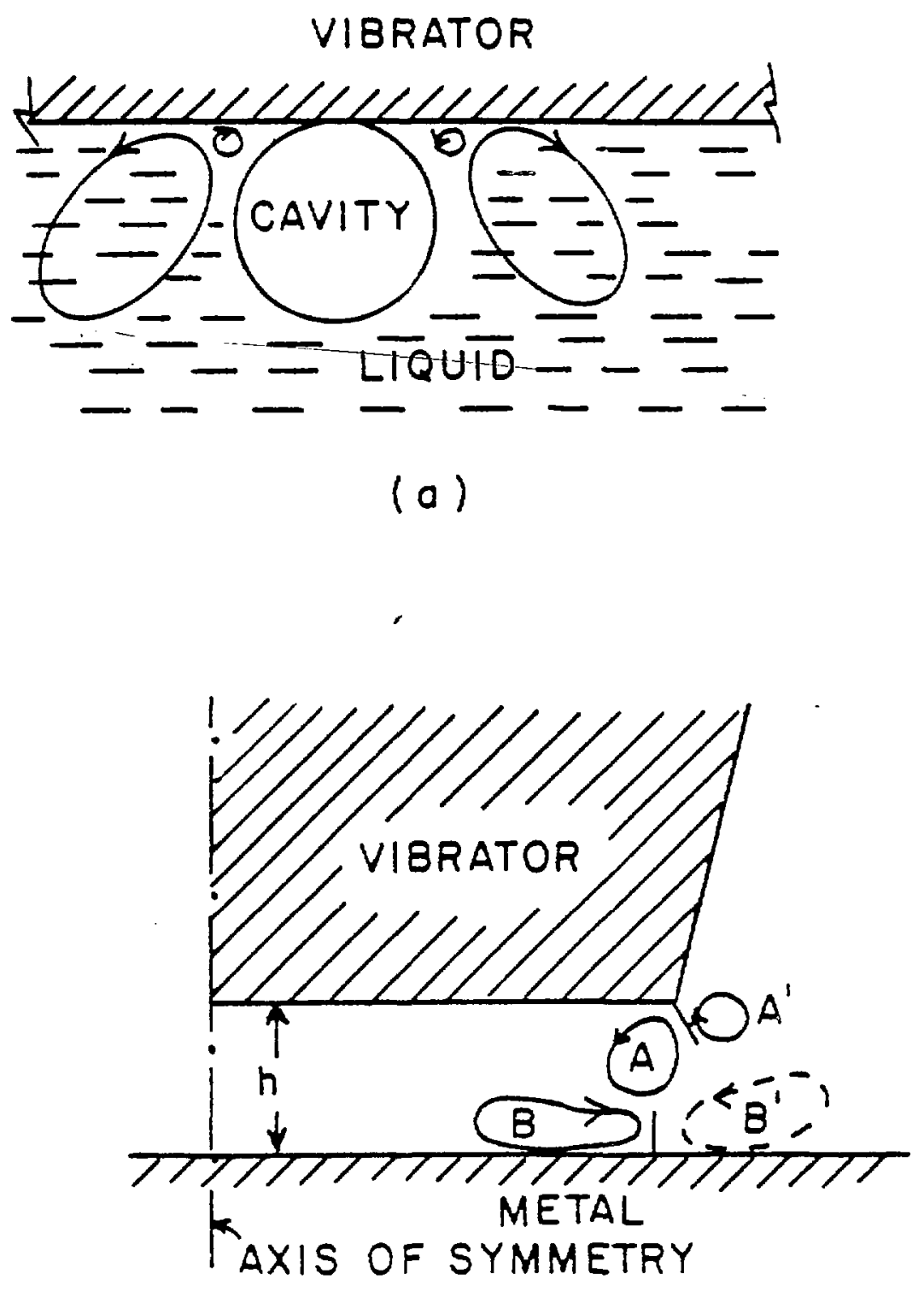

(b)

EIGURE 4. POssible microstreaming Ot the liguid (a) asscciated with a single resonant cavity attached to a vibratozy horn, and (b) at the edge of a vibratory horn wich is placed ata distarce, $h, \in=0 \pi \equiv$ plane solid surE ( Niyborg et ai., I959). 


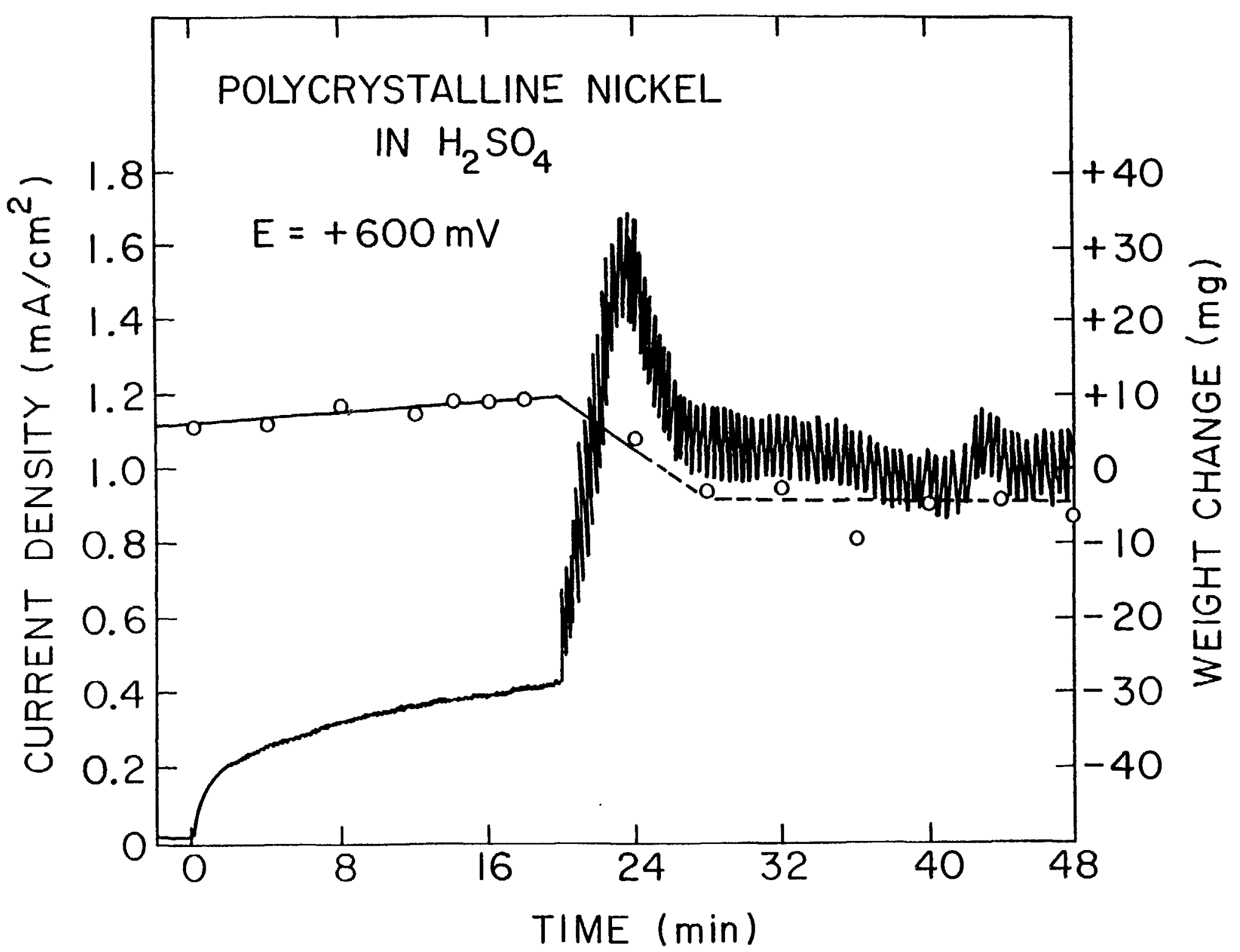

FIGURE 5. Change in current density and weight of a polished nickel sample held at a passive potential of $+600 \mathrm{mV}$ vs. SCE and exposed to ultrasonic cavitation (Preece and Vyas, 1974). 


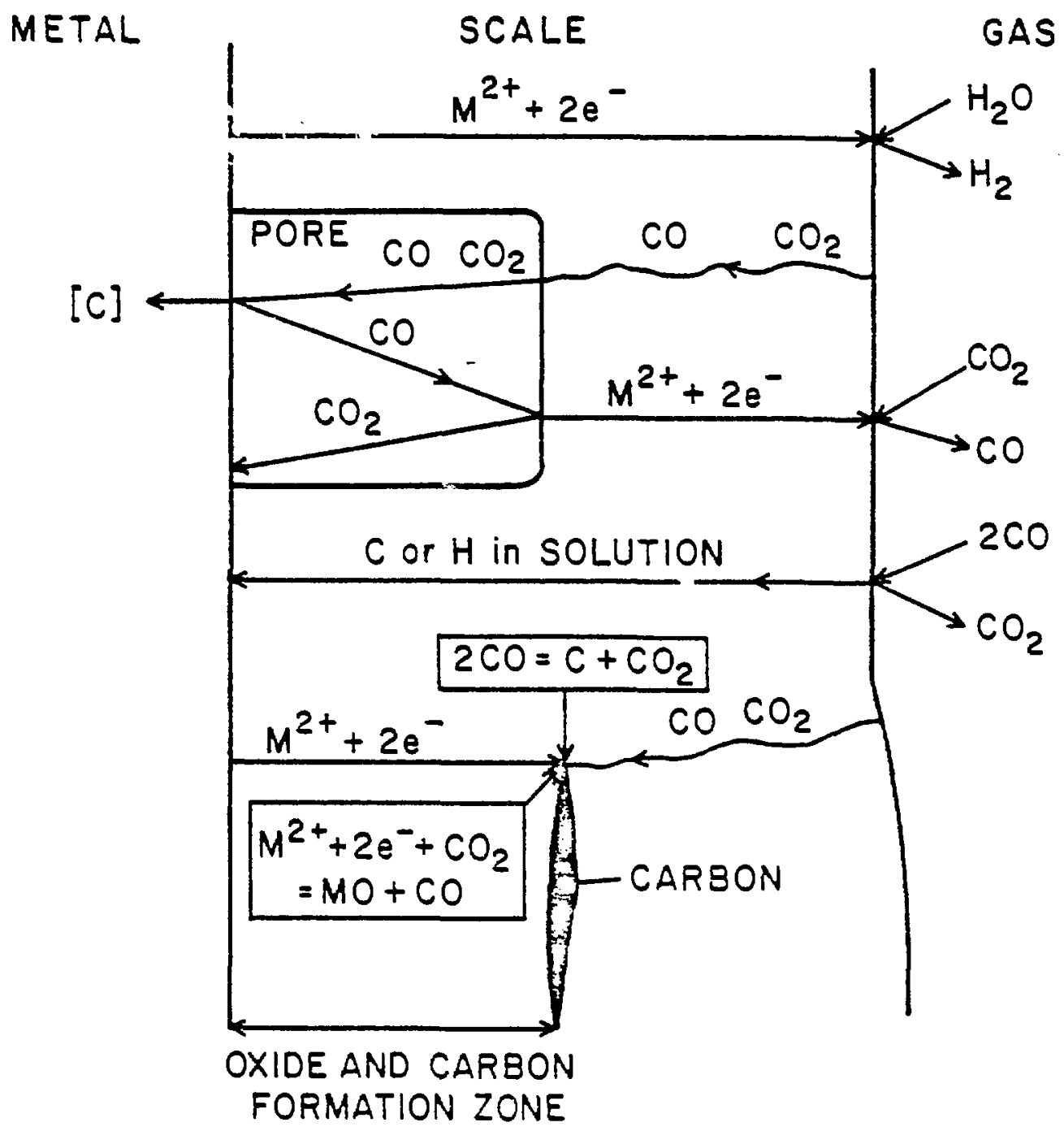

IEGT: 6. Possible modifications to oxidstion mechanisns due to $\mathrm{CO}_{2}$ and $\mathrm{H}_{2} \mathrm{O}$ being present in the atmosphez作 (3irks, 1975), "This Eigure was originali $\ddot{y}$ presented at the Eal1 ljotin Meeting of The ElectrocinenicaI Society, Inc., held in Las Vegas, Neraba." 

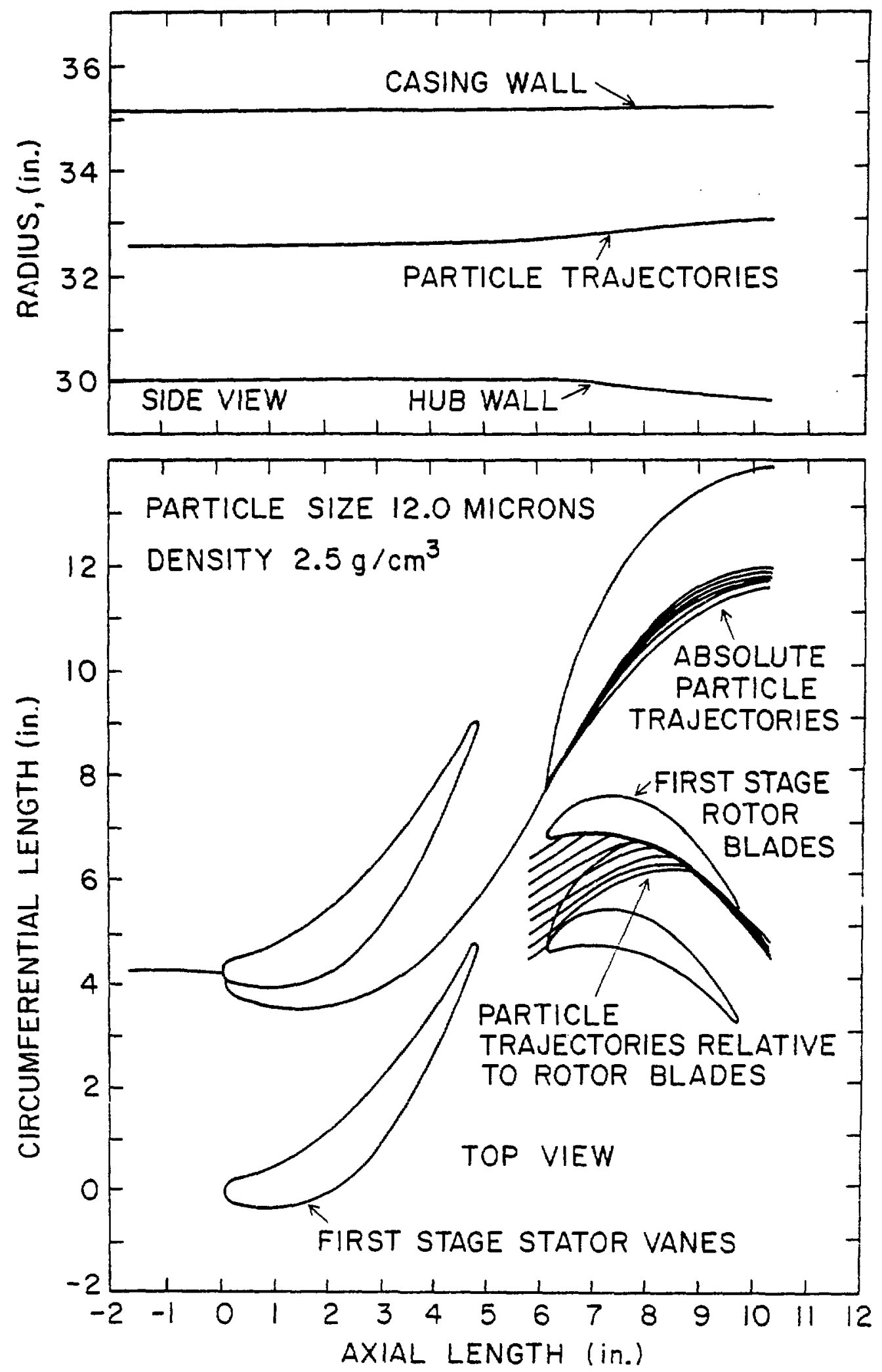

FIGURE 7. Main flow model of $13 \mathrm{\mu m}$ diameter particles in a gas turbine first stage (Spengler et al., 


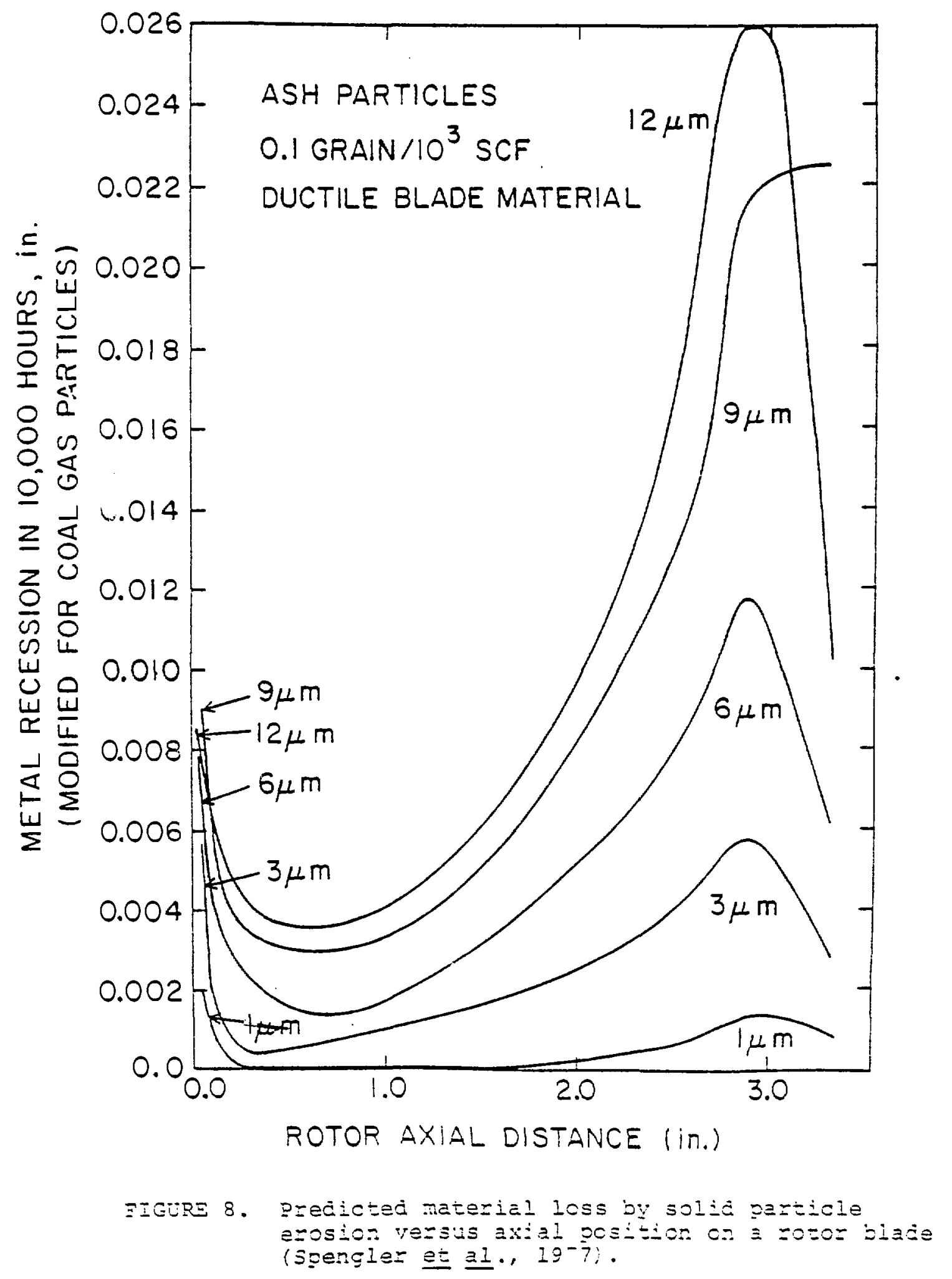



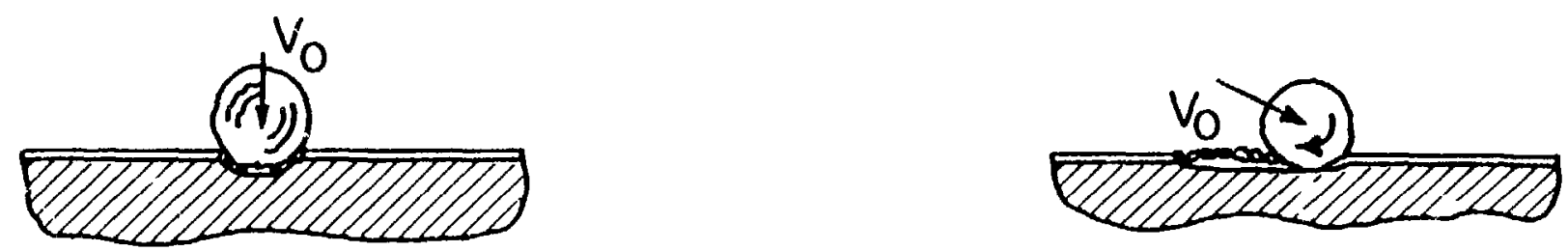

(a) TH!N OXIDE LAYER
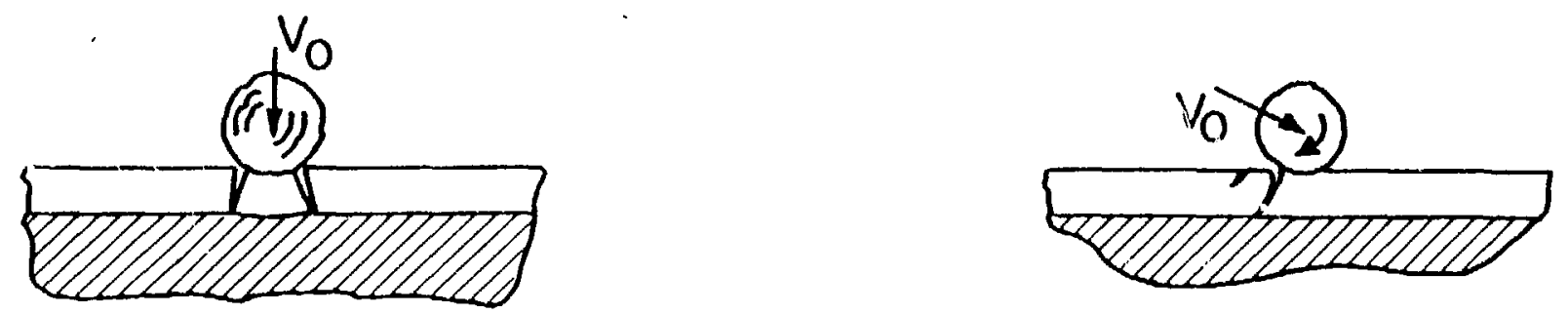

\section{(b) OXIDE LAYER COMPARABLE TO PARTICLE SIZE}

IIGURE 9. Interaction of oxide film thickness and particle diameter on the erosion-corrosion process when (a) the thickness of the oxide layer is small,

(b) the thickness of thu oxide layer is comparable so the particle diameter (Goebel et al., 1977 ). 